\title{
The performance of improved H-modes at ASDEX Upgrade and projection to ITER
}

\author{
A.C.C. $\operatorname{Sips}^{1}$, G. Tardini ${ }^{1}$, C.B. Forest ${ }^{2}$, O. Gruber ${ }^{1}$, P.J. Mc Carthy ${ }^{3}$, A. Gude ${ }^{1}$, L.D. Horton ${ }^{1}$, \\ V. Igochine ${ }^{1}$, O. Kardaun ${ }^{1}$, C.F. Maggi ${ }^{1}$, M. Maraschek ${ }^{1}$, V. Mertens ${ }^{1}$, R. Neu ${ }^{1}$,
} A.G. Peeters ${ }^{1}$, G.V. Pereverzev ${ }^{1}$, A. Stäbler ${ }^{1}$, J. Stober $^{1}$, W. Suttrop ${ }^{1}$ and the ASDEX Upgrade Team ${ }^{1}$

Max-Planck-Institut für Plasmaphysik, EURATOM-Association

Boltzmannstrasse 2

D-85748, Garching, Germany.

${ }^{1}$ Max-Planck-Institut für Plasmaphysik, EURATOM-Association, D-85748, Germany.

2 The University of Wisconsin, Madison, USA.

${ }^{3}$ Dep. of Physics, University College Cork, Association EURATOM-DCU, Cork, Ireland.

E-mail contact of the main author: ccs@ipp.mpg.de

\begin{abstract}
Since 1998 ASDEX Upgrade has developed stationary H-modes that routinely obtain confinement enhancement factors $H_{98(y, 2)}>1$ and normalised beta, $\beta_{\mathrm{N}}=2-3$. These discharges are characterized by a qprofile with low magnetic shear in the centre and $\mathrm{q}(0) \sim 1$. New results presented here concentrate on extending the operational range of these improved H-modes at ASDEX Upgrade and extrapolating the results to ITER. Discharges are obtained at high density, over a wide range of plasma collisionality and with a first wall predominantly covered by tungsten coated carbon tiles. The performance is optimised for $\mathrm{q}_{95}$ ranging from 3 to 5 . At $\mathrm{q}_{95} \sim 3$ real time control of $\beta_{\mathrm{N}}$ is used and in some cases ECCD to suppress NTM activity at low $\beta_{\mathrm{N}} \sim 2$. For the extrapolation to ITER, the fusion power is calculated using the same thermal beta $\left(\beta_{\mathrm{N}, \mathrm{th}}\right)$ and kinetic profile shapes as obtained in ASDEX Upgrade and setting $<\mathrm{n}_{\mathrm{e}}>/ \mathrm{n}_{\mathrm{GW}}=0.85$. The fusion gain that could be obtained is evaluated using different confinement scaling expressions. The results indicate that improved H-modes are a candidate for an ITER hybrid scenario or could extend ITER operation beyond what is currently foreseen using standard H-modes.
\end{abstract}




\section{Introduction}

In thermonuclear fusion research using magnetic confinement, the tokamak is the leading candidate for achieving conditions required for a reactor. A tokamak is inherently a pulsed experiment. To achieve steady state operation it would be necessary to decrease plasma current to minimise the need for non-inductive drive, increase plasma pressure to maximise both the fusion power and the bootstrap current fraction [1] and optimize external current drive sources to sustain the discharge. The stability of the plasma is governed by the plasma pressure obtained. An important definition is the ratio of the average plasma pressure to the total magnetic pressure $\langle\beta\rangle$, which can be normalised to obtain $\beta_{\mathrm{N}}\left(\beta_{\mathrm{N}}=\left\langle\beta>{ }_{\mathrm{aB}} / \mathrm{I}_{\mathrm{p}}\right.\right.$ in $\% \mathrm{mT} / \mathrm{MA}$ (where a is the minor radius of the tokamak, $\mathrm{B}_{\mathrm{T}}$ the toroidal field and $\mathrm{I}_{\mathrm{p}}$ the plasma current).

The best results in terms of plasma confinement for inductive (pulsed) operation are obtained in H-modes, a regime with a transport barrier for energy and particles at the edge of the plasma [2]. In stationary H-mode discharges, Edge Localised Modes (ELMs) are observed, that is periodic relaxations of the edge pressure gradient. A widely used, empirical scaling for the thermal energy confinement in ELMy H-mode plasmas has been published [3], called the IPB98(y,2) scaling expression. The ratio of the measured thermal energy confinement time $\left(\tau_{\mathrm{E}}\right)$ and predicted thermal energy confinement time $\left(\tau_{\mathrm{E}, 98(\mathrm{y}, 2)}\right)$ is defined as $\mathrm{H}_{98(\mathrm{y}, 2)}$; for standard $\mathrm{H}$-modes the value for $\mathrm{H}_{98(\mathrm{y}, 2)}$ should be near 1 .

An international experimental reactor, ITER, is planned as a first integration of the physics of plasmas heated predominantly by the confined alpha particles from the deuteriumtritium fusion reactions, and key technological requirements, in order to demonstrate fusion as a viable source for generating electricity [4]. The standard operation regime of ITER is based on the ELMy H-mode, owing to its reproducibility and the large experimental database from various experiments. ITER is designed using $\mathrm{H}_{98(\mathrm{y}, 2)}=1.0$ and a plasma current of 15 MA, to provide operation at a fusion power $\left(\mathrm{P}_{\text {fus }}\right)$ in the range $400-500 \mathrm{MW}$ and $\mathrm{Q}=10$, with $\mathrm{Q}$ defined as the ratio of the fusion power and the external heating power.

The inverse rotational transform of a magnetic flux surface, the safety factor $\mathrm{q}$, is an important parameter in tokamaks. This safety factor $q$ and the magnetic shear $s=(r / q) d q / d r$ (with $r$ the minor radius of the flux surface) play a key role in plasma stability and confinement. Typically, magnetohydrodynamic (MHD) instabilities are observed at or near rational q values. These MHD events generally can lead to significant reduction in confinement and limit the plasma performance. In the standard inductive operation mode of ITER, the safety factor increases monotonically with radius and $\mathrm{q}$ on the magnetic axis $(\mathrm{q}(0))$ 
is below unity. The safety factor close to the edge, at the $95 \%$ flux surface $\left(q_{95}\right)$, is 3 , a compromise between maximising the confinement (which scales linearly with $\mathrm{I}_{\mathrm{p}}$ ) and the increased risk of damage to the mechanical structures due to electromechanical forces during disruptions. Another requirement is operating at sufficiently high plasma density (near $\left.1.0 \times 10^{20} \mathrm{~m}^{-3}\right)$ to generate large enough fusion output power and to ensure the power exhaust with a reasonable lifetime of the divertor target. However, there is a limit to the maximum density in ELMy H-modes, above which the energy confinement drops sharply. This socalled Greenwald density limit for H-modes is defined as $\mathrm{n}_{\mathrm{GW}}=10^{20}\left[\mathrm{~m}^{-3}\right] \mathrm{I}_{\mathrm{p}}[\mathrm{MA}] / \pi^{2}\left[\mathrm{~m}^{2}\right][5]$. The line-averaged density $\left\langle\mathrm{n}_{\mathrm{e}}\right\rangle$ normalised to the Greenwald density limit, $\left\langle\mathrm{n}_{\mathrm{e}}\right\rangle / \mathrm{n}_{\mathrm{GW}}$, is set at 0.85 in the ITER design.

The operational space of the inductive reference scenario at $I_{p}=15$ MA has been assessed for a range of $\mathrm{H}_{98(\mathrm{y}, 2)}$ factors to determine the 'envelope' of performance within ITER's capabilities and physical constraints [6,7]. These show a strong dependence of $Q$ and $\mathrm{P}_{\text {fus }}$ with $\mathrm{H}_{98(\mathrm{y}, 2)}$, average plasma density and impurity concentration. Hence, a significant increase in ITER performance could be achieved with a relatively small improvement in energy confinement. As shown in Figure 1 (adapted from [7]) an increase in $\mathrm{H}_{98(\mathrm{y}, 2)}$ to a value of 1.3, although outside the confidence interval for the IPB98(y,2) scaling, would give $\mathrm{P}_{\text {fus }}$ near $800 \mathrm{MW}$ and $\mathrm{Q} \sim 20$. As a result, any discharge in ITER that achieves $\mathrm{H}_{98(\mathrm{y}, 2)}>1$ and is able to operate at higher beta compared to the ITER reference scenario can be used to increase the performance at $15 \mathrm{MA}$. Alternatively, these discharges at high confinement can be utilised for ITER operation at $\mathrm{I}_{\mathrm{p}}=11-14 \mathrm{MA}$, while keeping $\mathrm{Q}=5-10$. Moreover, $\mathrm{a}$ demonstration fusion reactor "DEMO", the next step after ITER, will require $\mathrm{H}_{98(\mathrm{y}, 2)}$ in the range 1.2-1.4 and $\beta_{\mathrm{N}}>3.5$ to be achieved routinely for economical operation of the plant [8]. Hence, ITER needs to confirm that these values are accessible reliably.

In the past ten years, a large effort has been made to develop regimes that could lead to fully non-inductive operation of a tokamak at high fusion yield, utilising the self generated (pressure driven) bootstrap effect. These scenarios typically rely on the formation of an internal transport barrier to improve the confinement. Sufficient bootstrap current may be provided in this way to satisfy ITER's second major goal of reaching $Q=5$ under fully noninductive conditions. However, achieving these conditions necessitate careful tailoring of the current density profile by the external heating and current drive methods. The stringent control requirements for discharges with internal transport barriers have prompted research into advanced operating scenarios that are inherently stationary with respect to the current relaxation time scale, imposing minimum control by external actuators. 
For ITER, it was originally envisioned [4] that discharges with extended burn at lower plasma current $\left(\mathrm{I}_{\mathrm{p}}<15 \mathrm{MA}\right)$ would be intermediate between the inductive burn (baseline) scenario and the fully non-inductive (steady state) scenario; therefore, this type of discharge is known as the ITER "hybrid" scenario. This would allow operation in a mode with high reliability and would maximise the neutron fluence (integrated neutron wall load during a pulse) in ITER for material testing. Several experiments $[9,10,11]$ have independently developed (stationary) H-modes with $\mathrm{q}(0) \sim 1$ exhibiting improved confinement factors, $\mathrm{H}_{98(\mathrm{y}, 2)}>1$ and good stability $\beta_{\mathrm{N}}=2-3$.

At ASDEX Upgrade [12,13,14,15,16] stationary H-mode discharges have been developed that are characterized by a q-profile with low magnetic shear in the centre and $q(0)$ $\sim 1$, typically obtained by applying heating during the current rise phase of the discharge. It has been found that discharges with $\mathrm{q}_{95}=3.8-4.4, \mathrm{q}(0) \sim 1$ and weak central shear can have an improved energy confinement compared to H-mode confinement scaling at high beta[13]. The q-profile characteristic of this scenario (called improved H-mode), compared to that of the standard inductive $\mathrm{H}$-mode scenario, prevents sawtoothing $\mathrm{m}=1 / \mathrm{n}=1 \mathrm{MHD}$ activity in the centre and the triggering of large $m=3 / n=2$ or $m=2 / n=1$ neo-classical tearing modes $((3,2)$ NTM and $(2,1)$ NTM, respectively). These discharges are candidates for the ITER hybrid scenario. Also other experiments (DIII-D [17], JT-60U [18] and JET [19]) have shown rapid progress in the development of this operational scenario in the past few years.

In this paper, an overview is given of improved H-modes in ASDEX Upgrade (section 2). New results presented here concentrate on extending the operational range of improved $\mathrm{H}-$ modes at ASDEX Upgrade. The performance is optimised at different values of the plasma collisionality and even at high density (section 3). The optimisation is made for a range of values for $\mathrm{q}_{95}$, most importantly at $\mathrm{q}_{95}=3$ (section 4 ). The strategies for operation and control of high beta plasmas are given, including the control of the NTM activity (section 5). The fusion power which could be obtained in ITER is estimated by scaling the kinetic profiles obtained in ASDEX Upgrade (section 6).

\section{An overview of improved H-modes at ASDEX Upgrade}

$\mathrm{H}$-mode operation at ASDEX Upgrade is achieved for a wide range of deuterium plasmas using predominantly neutral beam injection (NBI). The NBI system has four beam lines with $60 \mathrm{kV}$ injection energy and four beam lines at $93 \mathrm{kV}$, each delivering 2.5 MW (in deuterium), giving a total available power of $20 \mathrm{MW}$. The injection geometry of two neutral beam 
sources at $93 \mathrm{kV}$ enables off-axis power deposition of up to $5 \mathrm{MW}$. Ion Cyclotron Resonance Heating (ICRH) at $30 \mathrm{MHz}, 36 \mathrm{MHz}$ or $40 \mathrm{MHz}$ using a Hydrogen minority heating scheme can also be applied to the plasma with a maximum coupled power of $6 \mathrm{MW}$. In addition, four gyrotrons at $140 \mathrm{GHz}$ can be used to heat electrons (Electron Cyclotron Resonance Heating: ECRH) with a total power of $2.0 \mathrm{MW}$.

A scenario used to obtain high beta $\left(\beta_{\mathrm{N}}>2\right)$ in improved H-modes at ASDEX Upgrade is described in detail below (section 2.1). The collection of results for analysis is given and discussed in section 2.2. This is followed, in section 2.3, by a brief overview of the typical parameters achieved in standard H-modes and in improved H-modes. Operation of the scenario with a tungsten first wall is discussed at the end of this section (2.4).

\subsection{Operational scenario for the improved H-mode}

Heating during the current rise phase of a discharge raises the electron temperature and slows down the current penetration to the plasma centre. This operational scheme is generally used to obtain improved H-modes, although it is also possible to produce the desired q-profile (with flat shear in the centre and $\mathrm{q}(0) \sim 1$ ) under some conditions with heating during the flat top phase [20]. At ASDEX Upgrade a lower single null divertor configuration can be formed during the current rise phase at $\mathrm{t} \sim 0.5 \mathrm{~s}$, as shown in Figure 2 . In the phase before $t \sim 0.5 \mathrm{~s}$ a limiter configuration is used with the largest possible plasma cross section to minimise the current penetration. Forming the divertor configuration during the current rise allows operation at low plasma density $\left(<3 \times 10^{19} \mathrm{~m}^{-3}\right)$, minimises the impurity content, and allows application of additional heating (typically $2.5 \mathrm{MW} \mathrm{NBI).} \mathrm{The} \mathrm{rate} \mathrm{of} \mathrm{rise} \mathrm{of} \mathrm{the} \mathrm{plasma}$ current is not varied at ASDEX Upgrade and is close to the maximum $\mathrm{dI}_{\mathrm{p}} / \mathrm{dt} \sim 0.66 \mathrm{MA} / \mathrm{s}$, in line with the capabilities of the poloidal field coils and the preference to form the divertor configuration early in the discharge. By using such a scenario, a low magnetic shear in the centre is obtained at the beginning of the flat top phase of improved H-modes. Two, typical, examples of the q-profiles obtained during the flat top phase are shown in Figure 3. These qprofiles are calculated with the CLISTE equilibrium code [21] using magnetic data as input together with the measurements from the Motional Stark Effect (MSE) diagnostic [22] that has 10 observation channels in the inner region of the plasma. The MSE system is available again since 2006, after several hardware upgrades. The error bars for the reconstruction and the magnetic shear obtained are also shown. During the flat top phase, typically $50 \%$ of the neutral beam heating is directed off axis. However, according to neoclassical current diffusion calculations, $q(0)$ should be below 0.9 [23] and therefore the off axis neutral beam 
deposition would not be sufficient to keep $q(0) \sim 1$. Nevertheless, the measured q-profile remains stationary with low central shear throughout the discharge with $q(0)$ near 1 . MHD modes are thought to be responsible for keeping $q(0) \sim 1$. Typically $(3,2)$ NTMs (combined with higher $\mathrm{m} / \mathrm{n}$ activity) or $(1,1)$ fishbone activity in the centre are observed in improved $\mathrm{H}$ modes as described later in this paper.

\subsection{Selection of discharges for analysis}

For the analyses presented here, two datasets are created for $\mathrm{H}$-mode discharges with predominantly type I ELMs. The first dataset contains ELMy H-modes that have been used for physics studies in ASDEX Upgrade, such as edge pedestal studies, ELM studies, or confinement studies. Selected are discharges with plasma current $\mathrm{I}_{\mathrm{p}}=0.6-1.4 \mathrm{MA}$, toroidal field of $\mathrm{B}_{\mathrm{T}}=1.6-3.0 \mathrm{~T}, \mathrm{q}_{95}<5.5$, and stationary phases longer than 0.2 seconds (somewhat longer than the typical energy confinement time). The minor radius (a) of the discharges in the dataset lies between $0.49 \mathrm{~m}$ and $0.505 \mathrm{~m}$. This dataset includes some pulses that are heated during the current rise phase. The values for the parameters stored in the dataset are averaged for the time window selected. Figure 4 a shows the 944 data points in this first dataset with $\mathrm{H}_{98(\mathrm{y}, 2)}$ versus normalised beta $\left(\beta_{\mathrm{N}}\right)$. A wide range of $\mathrm{H}_{98(\mathrm{y}, 2)}$ is obtained at ASDEX Upgrade. The ITER reference scenario at 15MA is indicated in Figure $4 \mathrm{a}\left(\mathrm{H}_{98(\mathrm{y}, 2)}=1.0, \beta_{\mathrm{N}}=1.8\right)$. A second dataset is created containing only improved H-mode discharges in ASDEX Upgrade, i.e. plasmas with low magnetic shear in the centre. Selected are discharges with heating during the current rise (standard recipe to obtain low magnetic shear in the centre) with a range of plasma current $\mathrm{I}_{\mathrm{p}}=0.8-1.2 \mathrm{MA}$, of toroidal field $\mathrm{B}_{\mathrm{T}}=1.8-2.8 \mathrm{~T}$, and $\mathrm{q}_{95}=3-5.5$. The time scale of the evolution of the current profile is important for improved H-modes, hence only discharges that are stationary for more than 0.5 seconds are selected. A few pulses at $\mathrm{q}_{95}>4$ that achieve a q-profile typical of improved H-modes, but obtained without heating during the current rise phase, are also included. These conditions have been achieved in recent experiments [20] by applying strong heating during the flat top phase. The 259 data points in this second dataset are given in Figure 4b. Also indicated in Figure $4 \mathrm{~b}$ are the minimum requirements for a DEMO reactor as given in reference [8]. The dataset used gives an overview of all stationary, improved H-mode discharges obtained over the past few years. This dataset is not merely a collection of the best H-modes realised at ASDEX Upgrade, all the data available are shown for this scenario rather than the best the discharges that reach the highest beta or the highest confinement enhancement factors. This introduces scatter in the overview plots presented in this paper. Important however is that such a scatter is observed, 
especially when comparing the results to other experiments or making projections to ITER.

The two data sets are compared in Table I. The 944 observations in the type I ELMy H-mode database include also phases that achieve high beta and may have developed a qprofile with low magnetic shear in the centre. In H-mode discharges the pedestal has a significant contribution to the beta achieved [24], giving a considerable bootstrap current at the edge of the plasma. Consequently, some discharges at high beta included in the first dataset could be labelled as improved H-modes. However, since MSE measurements are not available for most of the discharges in the dataset, this could not be confirmed. The second dataset serves as a comparison by selecting solely attempts to establish an improved H-mode scenario at ASDEX Upgrade. In the future, physics criteria should be developed to distinguish between standard H-modes and improved H-modes. Given the importance of the current density profile, the plasma inductance may be used (e.g. $1_{\mathrm{i}}<0.95$ to identify improved $\mathrm{H}$-modes). This is not done here due to the uncertainty in the measurements, resulting from the unavailability of MSE data to constrain the equilibrium reconstruction with the CLISTE code.

\subsection{Typical parameters for improved H-modes}

On average improved $\mathrm{H}$-mode discharges achieve higher $\mathrm{H}_{98(\mathrm{y}, 2)}$ and higher $\beta_{\mathrm{N}}$ compared to standard H-modes (see Table I). By using heating during the current rise and maintaining the q-profile during the flat top phase, the average value of the plasma inductance $\left(l_{\mathrm{i}}\right)$ is lower $\left(l_{\mathrm{i}}=0.89\right)$, compared to the averaged $\mathrm{l}_{\mathrm{i}}=0.95$ for standard ELMy H-modes. However, magnetic measurements are used to evaluate $l_{i}$ (the majority of the discharges selected have no MSE data), leading to large scatter of the values obtained. Another difference between the two datasets is that improved H-mode discharges typically operate at somewhat lower density, $<\mathrm{n}_{\mathrm{e}}>/ \mathrm{n}_{\mathrm{GW}} \sim 0.54$ compared to standard H-modes. This is shown in Figure 5 where the

confinement enhancement factor $\mathrm{H}_{98(\mathrm{y}, 2)}$ is plotted versus $<\mathrm{n}_{\mathrm{e}}>/ \mathrm{n}_{\mathrm{GW}}$, together with the requirements for ITER $\left(\mathrm{H}_{98(\mathrm{y}, 2)}=1.0\right.$ and $\left.<\mathrm{n}_{\mathrm{e}}>/ \mathrm{n}_{\mathrm{GW}}=0.85\right)$. Improved $\mathrm{H}$-modes at higher density are obtained at ASDEX Upgrade by increasing the density after the formation of the qprofile, together with an increase in heating power. The datasets contain the complete triangularity range available at ASDEX Upgrade. The average triangularity (mean of upper and lower triangularity) ranges from 0.15 to 0.46 . As commonly observed in ELMy H-mode discharges $[25,26]$, only in configurations with high triangularity, $\delta=0.35-0.46$, good confinement is obtained for ITER relevant values of $<\mathrm{n}_{\mathrm{e}}>/ \mathrm{n}_{\mathrm{GW}}=0.85$. For improved $\mathrm{H}$-mode discharges at ASDEX Upgrade, $\mathrm{H}_{98(\mathrm{y}, 2)}$ up to 1.3 can be achieved at high density (see section 
$3)$.

\subsection{Operation with a tungsten first wall at ASDEX Upgrade}

Control of impurity influxes and impurity transport are important with the progressive increase in the area of the first wall covered by tungsten coated carbon tiles at ASDEX Upgrade. This is imperative for improved H-modes that typically operate at low density, at least during the current rise phase of the discharge, to achieve (and maintain) the desired qprofile. Since 2001 the surface area of tiles on the first wall with a tungsten coating has been increased to $36 \mathrm{~m}^{2}$ (2006), which is about $90 \%$ of the first wall surfaces, but not the lower divertor tiles [27], this is indicated in Figure 2. Considering all discharges in ASDEX Upgrade, the tungsten concentration in the centre of the plasma shows a steady rise since 2001 (Figure 6). The tungsten concentration is measured spectroscopically for the plasma region at $\mathrm{T}_{\mathrm{e}} \sim 2-4 \mathrm{keV}$ (core). The peak in the tungsten concentration observed in all plasmas around \#19000 was a result of a failed coating of one tile. This tile was replaced and operation resumed successfully. Most H-modes, including improved H-modes, have central tungsten concentrations below $10^{-4}$. This is considered acceptable for a reactor, provided the tungsten concentration at the plasma edge is kept below $10^{-5}$. However, central heating with ICRH or ECRH is necessary for avoiding impurity accumulation and achieving a low tungsten concentration $\left(<10^{-4}\right)$ [27]. Nearly all improved H-mode discharges in 2005 and 2006 use 1 to $3 \mathrm{MW}$ of ICRH minority heating, or $\sim 1 \mathrm{MW}$ of ECRH in addition to the neutral beam injection. Operation at the lowest plasma densities $\left(4-6 \times 10^{19} \mathrm{~m}^{-3}\right)$ in improved H-modes requires a boronisation prior to the experiments to minimise tungsten influxes. In addition, the boronisation allows the ICRH to be used to control the impurity concentration in the centre, as the sputtering of tungsten near the ICRH antennae is too high when the limiters are not covered by boron [28].

\section{Operation over a wide range in normalised collisionality $\left(v^{*}\right)$}

Typically H-mode discharges at high triangularity can operate close to the Greenwald density limit, while keeping $\mathrm{H}_{98(y, 2)}$ in the range 0.9-1.0 [25,26]. Improved H-mode discharges at high density were obtained by starting at low density during the current rise phase, and then carefully increasing the amount of additional heating together with the gas puff rate. Using a configuration with $\delta \sim 0.45$ at $800 \mathrm{kA}$, and $\mathrm{q}_{95}=3.5-4$ a value of $\left\langle\mathrm{n}_{\mathrm{e}}>/ \mathrm{n}_{\mathrm{GW}}=0.88\right.$ was realised with good confinement, $\mathrm{H}_{98(\mathrm{y}, 2)}=1.3$ [13]. These discharges are included in Figure 5, but were only achieved in a narrow operational space (at $\mathrm{I}_{\mathrm{p}}=800 \mathrm{kA}$ ). With the first wall covered by 
tungsten coated carbon tiles, it is important to obtain standard H-modes and improved Hmodes at high edge density $\left(\mathrm{n}_{\mathrm{e}, \mathrm{ped}}\right)$ to minimise the tungsten influxes over a wide operational range. Recent experiments have extended high density operation of improved H-modes to a plasma current of $1 \mathrm{MA}\left(\mathrm{q}_{95}=4\right)$. The best discharges achieve $<\mathrm{n}_{\mathrm{e}}>=1.1 \times 10^{20} \mathrm{~m}^{-3}\left(<\mathrm{n}_{\mathrm{e}}>/ \mathrm{n}_{\mathrm{GW}}\right.$ $=0.85-0.9)$, that is beyond the absolute densities required for ITER, while maintaining high performance: $\mathrm{H}_{98(\mathrm{y}, 2)}=1.2, \beta_{\mathrm{N}}=3.0$. In these discharges the measured density profiles are moderately peaked, with $\mathrm{n}_{\mathrm{e}, \mathrm{ped}} \sim 9.2 \times 10^{19} \mathrm{~m}^{-3}$ and the density in the centre, $\mathrm{n}_{\mathrm{e} 0} \sim 1.3 \times 10^{20} \mathrm{~m}^{-3}$. The density profile is reconstructed from a combination of diagnostic measurements: Thomson scattering in the centre and at the edge, lithium beam diagnostic measurements, and five horizontal viewing chords of the Deuterium-Carbon-Nitrogen (DCN) laser interferometer.

The results presented here can be compared to ITER using the normalised collisionality $\left(\mathrm{v}^{*} \sim \mathrm{a}^{7}<\mathrm{n}_{\mathrm{e}}>^{3} \kappa^{2} /\left(\varepsilon^{3} \mathrm{~W}^{2}\right)\right.$, with $\mathrm{W}$ the total stored energy, $\kappa$ the elongation of the plasma cross section, and $\varepsilon$ the inverse aspect ratio). When devices smaller than ITER, such as ASDEX Upgrade, operate at densities relevant for exhaust $\left(<\mathrm{n}_{\mathrm{e}}>/ \mathrm{n}_{\mathrm{GW}}=0.85-0.9\right)$ they run at relatively high collisionality, $v^{*} / v^{*}$ ITER $\sim 10$. Hence, it is important to study the confinement improvement over IPB98(y,2) scaling versus $v * /{ }^{*}{ }_{\text {ITER }}$ for standard H-modes and improved $\mathrm{H}$-modes covering a range of electron densities for varying $<\mathrm{n}_{\mathrm{e}}>/ \mathrm{n}_{\mathrm{GW}}$. As shown in Figure 7 , the highest values of $\mathrm{H}_{98(\mathrm{y}, 2)}$ are obtained at ITER relevant $\mathrm{v}^{*}$. Improved H-mode discharges are predominantly obtained close to ITER collisionality values and occupy the upper envelope of the operating space in Figure 7.

The improved H-mode discharges were particularly selected for long pulse operation (see selection criteria in section 2.2) and generally fall in a more restricted operational range compared to standard H-modes. There is however significant variation of the confinement enhancement factor at low $v^{*}$ that requires further clarification. Table II shows the results of improved H-mode discharges at 1.0MA, with similar $\mathrm{q}_{95} \sim 4$, at $v^{*} / v^{*}{ }_{\text {ITER }}=2.3-3$ showing a spread of $\mathrm{H}_{98(\mathrm{y}, 2)}$ of 1.01 to 1.45 . First, not all discharges with a typical improved H-mode qprofile are heated to high beta (like \#18046 in Table II). As given in [23], these discharge at $\beta$ ${ }_{\mathrm{N}} \sim 2$ remain at $\mathrm{H}_{98(\mathrm{y}, 2)} \sim 1$. Second, the NTM activity in improved H-modes is often small and contributes to keeping the q-profile stationary in ASDEX Upgrade [23]. There is however some penalty for having a $(3,2)$ NTM on $\mathrm{H}_{98(\mathrm{y}, 2)}$ related to the size of the mode obtained (although not quantified in this analysis). At low collisionality the discharges are more susceptible to strong $(3,2)$ NTM activity [29] and in these discharge the confinement 
enhancement factor may drop to 0.9-1.0 for improved H-modes at high beta $\left(\beta_{\mathrm{N}}>2\right)$. Finally, the best discharges at low $v^{*}$ with the highest $\mathrm{H}_{98(\mathrm{y}, 2)}$ presented in Table II and Figure 7 are dominated by fishbone activity. As given by Stober [20], improved H-mode discharges with fishbone activity systematically have the best confinement enhancement factors at ASDEX Upgrade $\left(\mathrm{H}_{98(\mathrm{y}, 2)}=1.4-1.5\right.$ at low $\left.\mathrm{v}^{*}\right)$. The difference in q-profiles obtained between a fishbone dominated improved $\mathrm{H}$-mode and a $(3,2)$ dominated improved H-mode is shown in Figure 3; the fishbone dominated discharge obtaining a flatter shear in the centre, while achieving higher shear for the region $\rho_{\text {tor }}=0.4-0.8$. The high density (high $v^{*}$ ) improved $\mathrm{H}$ modes always have fishbone activity [13], at low $v^{*}$ only a subset of the pulses. Therefore the discharges at the highest $\mathrm{H}_{98(\mathrm{y}, 2)}$ for the $\mathrm{v}^{*}$ range covered typically belong to a similar type of improved H-mode (with fishbone activity).

Another important dimensionless quantity is the ratio of the electron temperature $\left(T_{e}\right)$ to the ion temperature $\left(\mathrm{T}_{\mathrm{i}}\right)$. In most experiments high performance H-mode discharges are established using strong neutral beam heating at low plasma density so that the ion temperature is usually higher than the electron temperature. However, plasmas in ITER will operate with $\mathrm{T}_{\mathrm{i}} \sim \mathrm{T}_{\mathrm{e}}$. Hence, the results obtained in ASDEX Upgrade are important in two respects: (1) The use of RF heating, and (2) operation at high density. Both allow operation in the range $0.7<\mathrm{T}_{\mathrm{i} 0} / \mathrm{T}_{\mathrm{e} 0}<1.3$ as shown in Figure 8a, with $\mathrm{T}_{\mathrm{i} 0}, \mathrm{~T}_{\mathrm{e} 0}$ corresponding to the central ion and central electron temperatures reached. Especially the high density discharges described above achieve equal ion and electron temperatures in the centre $T_{i 0}=T_{e 0}=3 k e V$. However, a systematic study of the improved H-modes with increasing density, while keeping other parameters constant is not available for ASDEX Upgrade. In Figure 8a, six points with NBI only at $\mathrm{T}_{\mathrm{i} 0} / \mathrm{T}_{\mathrm{e} 0}>2$, still show a spread in $\mathrm{H}_{98(\mathrm{y}, 2)}$. As explained above, this difference comes from comparing five discharges with moderate $(3,2)$ NTM activity with confinement quality 1.0-1.2 and one discharge pulse with $\mathrm{H}_{98(\mathrm{y}, 2)}>1.4$ which has fishbone activity. While operating with $\mathrm{T}_{\mathrm{i} 0} \sim \mathrm{T}_{\mathrm{e} 0}$, no reduction in confinement is observed, as shown in Figure $8 \mathrm{~b}$ (no trend of $\mathrm{H}_{98(\mathrm{y}, 2)}$ with $\mathrm{T}_{\mathrm{i} 0} / \mathrm{T}_{\mathrm{e} 0}$ is observed). A detailed analysis of improved $\mathrm{H}$ mode discharges with varying RF/NBI mix is reported by Stäbler [15]. Shown in this reference are discharges where the net power to the ICRH antenna, $\mathrm{P}_{\text {ICRH }}=6 \mathrm{MW}$, exceeds the NBI power injected into the torus, $\mathrm{P}_{\mathrm{NBI}} \sim 4.5 \mathrm{MW}$ that achieve a stationary value of $\beta_{\mathrm{N}}=2.6$ with $\mathrm{T}_{\mathrm{i} 0} / \mathrm{T}_{\mathrm{e} 0} \sim 1$, at a confinement factor of $\mathrm{H}_{98(\mathrm{y}, 2)} \sim 1.2$, in support of the claims presented here using a broader dataset. 


\section{Operation at $\mathrm{q}_{95}=3-5$}

In previous studies of improved H-modes at ASDEX Upgrade different values for $\mathrm{q}_{95}$ were obtained by changing the toroidal field $\left(\mathrm{B}_{\mathrm{T}}=1.9 \mathrm{~T}-2.5 \mathrm{~T}\right)$ at fixed plasma current, $\mathrm{I}_{\mathrm{p}}=1 \mathrm{MA}$. Still, most improved H-mode experiments in ASDEX Upgrade are at $\mathrm{q}_{95}=3.8-4.4$. In recent studies $\mathrm{q}_{95}$ was varied from 3 to 5 by changing the plasma current at roughly fixed toroidal field $\left(\mathrm{B}_{\mathrm{T}}=2.0 \mathrm{~T}-2.1 \mathrm{~T}\right)$. Keeping $\mathrm{B}_{\mathrm{T}}$ constant allows the same $\mathrm{RF}$ heating schemes to be used for controlling the impurity concentration in the centre. A similar scheme for changing $\mathrm{q}_{95}$ is likely to be used in ITER, as the RF heating systems and the ferritic steel inserts for compensation of the toroidal field ripple are both optimised at the maximum toroidal field, $\mathrm{B}_{\mathrm{T}}=5.3 \mathrm{~T}$.

First, discharges at $\mathrm{q}_{95} \sim 5(0.8 \mathrm{MA} / 2.1 \mathrm{~T})$ have been obtained at high values of beta poloidal $(\sim 2)$. These discharges have similar MHD behaviour, stability and confinement compared to pulses at $\mathrm{q}_{95}=3.8-4.4$ reported previously [16]. ASTRA code [30] analysis of the kinetic data, including models for the bootstrap current $\left(\mathrm{I}_{\mathrm{BS}}\right)$ and beam driven current $\left(\mathrm{I}_{\mathrm{NBCD}}\right)$, estimate a non-inductive current drive fraction of $0.73\left(\mathrm{I}_{\mathrm{BS}} / \mathrm{I}_{\mathrm{p}}=0.4, \mathrm{I}_{\mathrm{NBCD}} / \mathrm{I}_{\mathrm{p}}=0.33\right)$. The noninductive current contributions alone sustain a current density profile with $q(0)$ just above 1 . Therefore discharges with $\mathrm{q}_{95}$ well above 5 would allow operation close to fully noninductive conditions. However, in H-modes the overall confinement, performance and capability to operate at sufficiently high densities all scale strongly with the plasma current $I_{p}$. Operation at $\mathrm{q}_{95}>5$ would imply a further reduction of the plasma current in ITER, which results in a too low plasma density (for $<\mathrm{n}_{\mathrm{e}}>/ \mathrm{n}_{\mathrm{GW}}<1$ ) and too low performance of these plasmas $(\mathrm{Q}<5)$. This statement is particularly apparent from the projections of ITER performance presented in section 6 of this paper.

Discharges at low $\mathrm{q}_{95}(\sim 3)$ are achieved in ASDEX Upgrade by increasing the plasma current to $1.2 \mathrm{MA}\left(\mathrm{B}_{\mathrm{T}}=2.0 \mathrm{~T}\right)$. The results obtained at these low values for $\mathrm{q}_{95}$ are important and are given in detail. Figure 9 shows an example of a discharge at $\mathrm{q}_{95}=3.17$ (\#20449). In this improved H-mode discharge, during the current rise to $1 \mathrm{MA}\left(\mathrm{dI}_{\mathrm{p}} / \mathrm{dt}=0.66 \mathrm{MA} / \mathrm{s}\right)$ the plasma is in the divertor configuration from $\mathrm{t}=0.5 \mathrm{~s}$ onwards with $2.5 \mathrm{MW}$ NBI heating. The current rise from $\mathrm{I}_{\mathrm{p}}=1.0 \mathrm{MA}$ to $1.2 \mathrm{MA}$ uses $5 \mathrm{MW} \mathrm{NBI}$ while $\mathrm{dI}_{\mathrm{p}} / \mathrm{dt}$ is reduced to $0.4 \mathrm{MA} / \mathrm{s}$ to prevent the occurrence of MHD instabilities (external kinks) due to high edge currents. In this discharge equal amounts of central and off-axis neutral beam heating (current drive) are used and in addition $1.8 \mathrm{MW}$ of ICRH power is applied to minimise the central impurity concentration. Feedback control of beta $\left(\beta_{\mathrm{N}}\right)$ is used (with $\mathrm{P}_{\mathrm{NBI}}$ as actuator), starting at $\mathrm{t}=1.7 \mathrm{~s}$ 
to avoid detrimental MHD modes or the formation of an internal transport barrier. In this operational scenario, the steepening of the pressure gradient in the centre due to an internal transport barrier poses a risk of a disruption. The discharge reaches $\beta_{\mathrm{N}}=2.9$ and is stationary for $1.5 \mathrm{~s}$ (10 energy confinement times), limited by the duration of the additional heating. During the high beta phase, the tungsten concentration in the centre is $2.5 \times 10^{-5}$, for $<\mathrm{n}_{\mathrm{e}}>=6.4 \times 10^{19} \mathrm{~m}^{-3}$ and $<\mathrm{n}_{\mathrm{e}}>/ \mathrm{n}_{\mathrm{GW}}=0.42, \mathrm{v} * / \mathrm{v}^{*}{ }_{\mathrm{ITER}}=2$, with the ratio $\mathrm{T}_{\mathrm{i} 0} / \mathrm{T}_{\mathrm{e} 0} \sim 1.4$. After 2 seconds, $\mathrm{n}=1$ MHD modes are observed, dominated by fishbone activity that remains throughout the

high power heating phase, indicating that $\mathrm{q} \sim 1$ in the centre. Also a $(4,3)$ NTM is observed, however throughout discharge there are no sawteeth present. These MHD modes can be seen in Fourier spectra taken from fast soft X-ray data as shown in Figure 10. It is reported in [20] that improved H-modes without $(3,2)$ NTM activity (as observed in this discharge for $\mathrm{t}>$ 2.3s) reach the highest values of $\mathrm{H}_{98(\mathrm{y}, 2)}$ observed in stationary discharges in ASDEX Upgrade. In \#20449, $\mathrm{H}_{98(\mathrm{y}, 2)}$ continues to rise with increasing beta, until $\mathrm{H}_{98(\mathrm{y}, 2)}=1.4$ at $\beta_{\mathrm{N}}=2.9$. Thus, this pulse displays a significant increase in performance compared to standard H-mode discharges.

\section{Operation at high beta: Limits and control of NTMs}

Improved H-modes at low $\mathrm{q}_{95}$ have fishbone activity at high beta $\left(\beta_{\mathrm{N}} \sim 2.5-3.5\right)$. Despite using control for the evolution of $\beta_{\mathrm{N}}$, this type of discharges consistently develop $(3,2)$ NTM modes when $\beta_{\mathrm{N}}$ is increased above 2 during the first few seconds of the discharge. A characteristic of $(3,2)$ NTM activity at low $\mathrm{q}_{95}<3.5$ is that the impact on confinement is generally stronger compared to improved $\mathrm{H}$-mode discharges at higher $\mathrm{q}_{95}>4$ [31]. In the example given before at $\mathrm{q}_{95}=3.17$ (Figure 9) the $(3,2)$ NTM mode is seen on magnetic probe signals from 1.7 to 2.3 seconds. This NTM behaviour is reproducible using the same discharge set-up. However, the spontaneous stabilisation of the $(3,2)$ NTM in \#20449 is not fully understood, in some discharges the NTM grows in amplitude leading to a deterioration of the energy confinement and in most cases to a $(2,1)$ NTM.

The effect and control of $(3,2)$ NTMs is studied in detail in two similar discharges at 1.2MA/2.0T (\#21269 and \#21272) that reproduce the conditions of \#20449. The time evolution of these two pulses is compared in Figure 11. In both pulses a $(3,2)$ NTM starts spontaneously (without sawteeth trigger) around $t=1 \mathrm{~s}$, growing in size until $t=2.0 \mathrm{~s}$ In \#21269, 1 MW of electron cyclotron current drive (ECCD) in direction of the plasma current was deposited near the $q=3 / 2$ surface at $\rho_{\text {pol }}=0.77$ (with $\rho_{\text {pol }}$ the normalised poloidal 
flux radius). With the application of co-ECCD starting at 2.0 seconds, the $(3,2)$ NTM is stabilised rapidly. No ECCD was applied in the second discharge (\#21272). Without ECCD the $(3,2)$ NTM remains, deteriorating the plasma confinement, and leading to a $(2,1)$ NTM that grows and locks. When this occurs, the plasma protection system triggers an impurity gas injection to induce a mild disruption. In Figure 12 the profiles of the electron temperature, the ion temperature and the electron density are shown just before and just after the stabilisation of the $(3,2)$ NTM in $\# 21269$. These profiles are obtained from fits to various diagnostic measurements available at ASDEX Upgrade. The kinetic profiles recover inside the deposition radius of the ECCD after the NTM is stabilised. The ECCD deposition is also shown in Figure 12d.

\section{Extrapolation to ITER}

Simulation codes can be used to predict the performance in ITER. These codes require models for transport in the plasma, models for the power deposition of the actuators and various supplemental models (e.g. fusion power, non-inductive current distribution). However, credible predictions of ITER performance depend on the successful validation of simulation codes on existing experiments. Moreover, since large extrapolations from conditions in present plasmas to burning plasmas are needed, it is important to base the predictions on rigorous calculations using physics based models (that also require validation on existing experiments). Typically, these physics-based predictive models are used to simulate the kinetic profiles. The performance of the standard ITER scenario at 15MA has been assessed [6,7] using an assumption for the density profile and by calculating the temperatures in the plasma, these profiles are shown in Figure 13. Here the transport model used is adjusted to obtain $\mathrm{H}_{98(\mathrm{y}, 2)}=1.0$, producing $\sim 400 \mathrm{MW}$ of fusion power for $40 \mathrm{MW}$ input power $(\mathrm{Q}=10)$. Plasmas that are candidates for the ITER hybrid scenario appear more challenging for the transport models used than standard H-mode plasmas as they generally have higher confinement and $\beta_{\mathrm{N}}$, a wider variety of magnetic shear in the centre and interaction of the observed MHD with the current density profile obtained [20], making predictions for ITER more uncertain.

In another approach, the measured kinetic profiles in the experiments are scaled to ITER, preserving the profile shapes or gradient lengths that are determined by the transport. Moreover, the pedestal region is also scaled. For most predictive simulations described above the pedestal height is an assumed boundary condition and very often a free parameter in the predictions for ITER, even though the pedestal region sometimes contains $40 \%-50 \%$ of the 
total stored energy [24]. The method presented here takes the measured profiles in ASDEX Upgrade, applies a set of rules for the scaling to ITER and uses the ASTRA code to evaluate the results. The ASTRA code is used here as it contains several modules for calculating the fusion power, Q, and bootstrap current fraction, once the kinetic profiles are known. By using the profiles shown in Figure 13 as input, the ASTRA code has been benchmarked [32] to reproduce (within small numerical error bars) the fusion power and Q quoted in [7]. In this paper, results are calculated for 68 ASDEX Upgrade discharges, with $\mathrm{q}_{95}=3.15-4.8$, $\mathrm{H}_{98(\mathrm{y}, 2)}=0.95-1.65$. The improved H-modes discharges in this dataset span a range of $\beta_{\mathrm{N}}$ from 1.7-3.5. The lower beta discharges do not represent the best improved H-modes at ASDEX Upgrade, but are included here as these type of ELMy H-modes were originally envisaged for hybrid operation in ITER [4]. In addition several standard H-mode discharges at $\beta_{\mathrm{N}} \sim 2$, are included in this dataset, heated after the onset of the sawteeth, at a range of $\mathrm{q}_{95}=3 \cdot 1-4.6$. For all of these 68 discharges good profile data have been acquired, as most of the discharges were repeated to get the best measurements of the core and edge region of the plasma. Hence this is only a subset of the data shown in the previous sections. The density and temperature profiles are obtained from a fit to the data of several diagnostics. The thermal beta determined from the kinetic profiles $\left(\beta_{\mathrm{N}, \mathrm{th}}\right)$ is somewhat lower than the total beta, which is consistent with measurements as the total stored energy includes fast particles: $\beta_{\mathrm{N}, \text { th }}$ is typically $0.8-0.9 \beta_{\mathrm{N}}$.

Various assumptions can be made to scale ASDEX Upgrade experiments to ITER [32]. A similar method has been used for DIII-D discharges [33]. The toroidal field (5.3T) and the equilibrium boundary are taken from the ITER design [4]. The plasma current in ITER is chosen to match the $\mathrm{q}_{95}$ used in ASDEX Upgrade, and varies from $\mathrm{I}_{\mathrm{p}}=14.2 \mathrm{MA}$ down to $\mathrm{I}_{\mathrm{p}}=9.4 \mathrm{MA}$ for the range of $\mathrm{q}_{95}=3.15-4.8$ of the 68 discharges selected. The shape of the density profile is taken as measured in ASDEX Upgrade, the scaling factor is adjusted to obtain $<\mathrm{n}_{\mathrm{e}}>=0.85 \mathrm{n}_{\mathrm{GW}}$ in ITER. At ASDEX Upgrade H-modes have good confinement over a range of $\left\langle\mathrm{n}_{\mathrm{e}}>/ \mathrm{n}_{\mathrm{GW}}\right.$ (see Figure 5). As a result choosing $\left\langle\mathrm{n}_{\mathrm{e}}>=0.85 \mathrm{n}_{\mathrm{GW}}\right.$ for ITER while keeping the same $\mathrm{H}_{98(\mathrm{y}, 2)}$ factor is valid, even though the ASDEX Upgrade pulses mainly operate at $<\mathrm{n}_{\mathrm{e}}>\sim(0.4-0.6) \mathrm{n}_{\mathrm{GW}}$ (note that $\mathrm{v}^{*}$ is close to ITER in these conditions). Electron and ion temperatures are assumed to be equal in ITER. The shape of the temperature profiles is taken to be equal to the measured profiles in ASDEX Upgrade. Either the ion temperature profile or the electron temperature profile is used. The ion temperature profile from ASDEX Upgrade is taken when $T_{i 0}>T_{e 0}$, and the electron temperature profile is taken when $T_{i 0} \leq T_{e 0}$. Usually, the temperature gradient lengths are quite close to each other in H-mode plasmas, some 
differences are observed at the lowest plasma densities (at high $\mathrm{T}_{\mathrm{i} 0}$ ). The value for ion and electron temperature (maintaining the shape) is adjusted to match the $\beta_{\mathrm{N}, \text { th }}$ value obtained in the ASDEX Upgrade discharges, the density profile required for this calculation having already been set. It is assumed that similar $\beta_{\mathrm{N}, \text { th }}$ values can be achieved, although the normalised Larmor radius $\rho^{*}$ is substantially lower in ITER, which could make discharges more susceptible to NTM activity [31]. The deuterium and tritium concentrations are assumed to be equal. Impurity concentrations are taken from the ITER design [3]: Beryllium $2 \%$, argon $0.12 \%$, helium $4.3 \%$. As a result, the volume averaged $\mathrm{Z}_{\text {eff }}$ is approximately 1.65 in all simulations, and the dilution of the tritium and deuterium fuel is $\sim 0.8$.

The density profiles and temperature profiles obtained for ITER by applying this method for extrapolation are shown in Figure 14. The projections for three distinct discharges are shown here: (a) A standard H-mode plasma (\#17847), (b) an improved H-mode (\#20449, see section 4) and (c) an improved H-mode (\#20448) at $\mathrm{q}_{95}=4.6$. Parameters for these shots and the projected parameters for ITER are listed in Table III. The kinetic profiles are compared to the simulated profiles for the ITER reference scenario at 15MA (shown in Figure 13), observing various differences. First, the scaled density profile is peaked, while the density profile used in the code simulations of the ITER reference scenario at 15MA is flat. Typically the improved H-modes operate at low $\mathrm{v}^{*}$. Analysis of JET and ASDEX Upgrade data have shown $[34,35]$ that the peaking of the density profile increases at lower $v^{*}$, hence this trend is contained in the extrapolations made here. Second, for the discharges at $\mathrm{q}_{95} \sim 3$, the temperature profiles in the outer region $\left(1.2 \mathrm{~m}<\mathrm{r}_{\min }<1.8 \mathrm{~m}\right)$ of the scaled ASDEX Upgrade data have steeper gradients compared to the code simulations of the ITER reference scenario at $15 \mathrm{MA}$. The codes used in these simulations predict a high transport for this region, which may not be correct for ITER. Figure $14 \mathrm{c}$ shows that at $\mathrm{q}_{95}=4.6$ the scaled profiles and profiles from the code simulation are more similar, hence the heat transport model used for the simulations of the ITER reference scenario at 15MA seems more suited for plasmas at low density with strong NBI heating as used for \#20448 in Figure 14c.

The fusion power in ITER can be calculated directly from the scaled kinetic profiles. Table III gives an overview of the projections to ITER for three improved H-mode discharges and one standard H-mode. These improved H-modes are among the best discharges $\left(\mathrm{H}_{98(\mathrm{y}, 2)}\right.$, and total beta) for a range of $\mathrm{q}_{95}$, the standard H-mode is closest to the ITER conditions $\left(\mathrm{q}_{95}=3.1\right.$, and other parameters, see Table III). An overview of the results for the whole database is given in Figure 15. In this figure, different symbols are used for improved H- 
mode discharges with $\beta_{\mathrm{N}}>2$, the improved H-modes at low beta $\beta_{\mathrm{N}} \leq 2$, and the five standard H-mode discharges. Moreover, the discharges given in Table III are indicated. The maximum fusion power obtained ranges from $420 \mathrm{MW}$ at $\beta_{\mathrm{N}, \mathrm{th}}=2.6$ and $\mathrm{I}_{\mathrm{p}}=9.4 \mathrm{MA}$ to $1070 \mathrm{MW}$ at $\beta$ $\mathrm{N}, \mathrm{th}=2.8$ (\#20499) and $\mathrm{I}_{\mathrm{p}}=14.2 \mathrm{MA}$ in ITER. These extrapolations indicate that operation at high beta results in significant fusion power for $\mathrm{I}_{\mathrm{p}}=9.5 \mathrm{MA}$ to $\mathrm{I}_{\mathrm{p}}=12 \mathrm{MA}$ in ITER, the operational range envisaged for the hybrid scenario. The bootstrap current fraction at these plasma currents is $f_{B S} \sim 0.4$ at $\beta_{N} \sim 3$. Alternatively, the results at low $q_{95} \sim 3\left(I_{p}=14-15 \mathrm{MA}\right)$ indicate that the fusion power could be more than doubled compared to the ITER reference scenario, moreover these discharge would obtain ignition $(\mathrm{Q}=\infty)$ for any of the three energy confinement scalings used here (see below). For the highest fusion power obtained at $\mathrm{q}_{95} \sim$ 3.1, the pedestal conditions (scaled from the ASDEX Upgrade profiles) remain within the ITER design parameters [36], with $\mathrm{n}_{\mathrm{e}, \mathrm{ped}}=6.8 \times 10^{19} \mathrm{~m}^{-3}$ along with the ion temperature $\left(\mathrm{T}_{\mathrm{i}, \mathrm{ped}}\right)$ and electron temperature $\left(\mathrm{T}_{\mathrm{e}, \mathrm{ped}}\right)$ at the pedestal $\mathrm{T}_{\mathrm{e}, \mathrm{ped}}=\mathrm{T}_{\mathrm{i}, \mathrm{ped}}=5.7 \mathrm{keV}$,

An estimate for the required input power $\left(\mathrm{P}_{\text {aux }}\right)$ and $\mathrm{Q}$ depends on the energy confinement. In Figure 15 the IPB98(y,2) scaling expression is used, assuming the same $\mathrm{H}_{98(\mathrm{y}, 2)}$ values are obtained in ITER and ASDEX Upgrade. Figure 16 shows the amount of auxiliary power required as a function of the plasma current and the confinement enhancement factor. Clear is that in ITER only discharges with good energy confinement, either by operating at high plasma current or sufficiently high $\mathrm{H}_{98(\mathrm{y}, 2)}$, are achievable with the heating power foreseen $\left(\mathrm{P}_{\mathrm{aux}} \leq 73 \mathrm{MW}\right)$.

However, the results obtained above depend on the energy confinement scaling expression used in the analyses. Hence, the fusion gain and input power $\left(\mathrm{P}_{\text {aux }}\right)$ required have been calculated for three different energy confinement scalings: The most commonly used IPB98 $(\mathrm{y}, 2)$ [3] indicated by $\tau_{\mathrm{E}, 98(\mathrm{y}, 2)}$, an electro-static gyro-Bohm scaling law derived in [37] denoted by $\tau_{\mathrm{E}, \mathrm{ESGB}}$ and a newly derived scaling by Cordey et al. [38] denoted by $\tau_{\mathrm{E}, \text { Cordey }}$

$$
\begin{aligned}
& \tau_{\mathrm{E}, 98(\mathrm{y}, 2)}=0.145 \mathrm{H}_{98(\mathrm{y}, 2)} \mathrm{I}_{\mathrm{p}}^{0.93} \mathrm{~B}_{\mathrm{T}}^{0.15} \mathrm{P}_{\text {heat }}{ }^{-0.69} \mathrm{n}^{0.41} \mathrm{M}^{0.19} \mathrm{R}^{1.39} \mathrm{a}^{0.58} \kappa^{0.78} \\
& \tau_{\mathrm{E}, \mathrm{ESGB}}=0.0865 \mathrm{H}_{\mathrm{ESGB}} \mathrm{I}_{\mathrm{p}}{ }^{0.83} \mathrm{~B}_{\mathrm{T}}{ }^{0.07} \mathrm{P}_{\text {heat }}{ }^{-0.55} \mathrm{n}^{0.49} \mathrm{M}^{0.14} \mathrm{R}^{1.81} \mathrm{a}^{0.30} \kappa^{0.75} \\
& \tau_{\mathrm{E}, \text { Cordey }}=0.092 \mathrm{H}_{\text {Cordey }} \mathrm{I}_{\mathrm{p}}^{0.85} \mathrm{~B}_{\mathrm{T}}^{0.17} \mathrm{P}_{\text {heat }}{ }^{-0.45} \mathrm{n}^{0.26} \mathrm{M}^{0.11} \mathrm{R}^{1.21} \mathrm{a}^{0.39} \kappa^{0.82}
\end{aligned}
$$


In the equations above $\mathrm{n}$ is the density in units of $10^{20} \mathrm{~m}^{-3}, \mathrm{R}$ is the major radius in $\mathrm{m}$, a is the minor radius in $\mathrm{m}, \mathrm{M}$ is the averaged ion mass in $\mathrm{AMU}, \kappa=\mathrm{A} / \pi \mathrm{a}^{2}$ is the plasma elongation, $A$ is the area of the poloidal cross section, and $P_{\text {heat }}$ the net heating power in MW. In the extrapolation to ITER, the respective H-values for each scaling obtained at ASDEX Upgrade are taken. The results are shown in Figure 17. For the IPB98(y,2) scaling, operation at high beta would require, in some cases, a value for $\mathrm{P}_{\mathrm{aux}}$ which is above the maximum planned for the first stage in ITER (73MW). These are indicted by the open symbols in figures 15 and 17. This is a characteristic of the IPB98(y,2) scaling law which has a strong beta degradation $(\mathrm{B} \tau$ $\left.{ }_{E} \sim \beta^{-0.9}\right)$; this scaling maximises $Q$ at the lowest possible beta. Especially for high $q_{95}\left(I_{p}\right.$ in ITER $<11 \mathrm{MA})$, the extrapolation using the IPB98(y,2) scaling predicts that discharges at $\beta$ ${ }_{\mathrm{N}}>2.5$ are inaccessible (not enough input power available) at $<\mathrm{n}_{\mathrm{e}}>=0.85 \mathrm{n}_{\mathrm{GW}}$ even for $\mathrm{H}_{98(\mathrm{y}, 2)}=1.3-1.5$. The fusion gain and fusion power in ITER are also evaluated in [39] by means of analytic expressions using confinement enhancement factors for different scaling expressions, $\beta_{\mathrm{N}}$ and $\mathrm{q}_{95}$. The results in [39] provide similar predictions, using the $\operatorname{IPB} 98(\mathrm{y}, 2)$ scaling, that some discharges at high beta $\left(\beta_{\mathrm{N}}>2.5\right)$ will not be accessible in ITER due to the lack of heating power. The result that some operational ranges are not accessible in ITER due to the availability of limited additional heating power, and the requirement to operate at $<\mathrm{n}_{\mathrm{e}}>=0.85 \mathrm{n}_{\mathrm{GW}}$ are not apparent from the performance indicator $\mathrm{H}_{98(\mathrm{y}, 2)} \beta_{\mathrm{N}} / \mathrm{q}_{95}{ }^{2}$, as is often used to assess discharges obtained in advanced scenarios in present day experiments. Moreover, reference [39] gives more details on the correct use of performance indicators. From the results shown in Figure 17, far more optimistic values for $\mathrm{P}_{\text {aux }}$ and $\mathrm{Q}$ are obtained using a GyroBohm scaling [37] $\left(\mathrm{B} \tau_{\mathrm{E}} \sim \beta^{0}\right)$. Also the scaling proposed by Cordey in 2005 [38] $\left(\mathrm{B} \tau_{\mathrm{E}} \sim \beta^{0}\right)$ would predict higher $\mathrm{Q}$ at high beta compared to the IPB98 $(\mathrm{y}, 2)$ scaling expression $\left(\mathrm{B} \tau_{\mathrm{E}} \sim \beta^{-}\right.$ $0.9)$.

The results obtained in this paper can be compared to results from DIII-D given by Wade in 2005 [40]. In this reference hybrid discharges are reported at high beta, with good confinement quality under stationary conditions. Also in DIII-D these discharge have been obtained over a wide range of $\mathrm{q}_{95}(2.8-4.7)$ and plasma density (35-70\% of the Greenwald density). The projections of the DIII-D results to ITER use a similar method as described in this section of the paper (as both are based on [33]) and indicate that a wide range of operating options may be available on ITER, including the possibility of sustained ignition for hybrid discharges at low $\mathrm{q}_{95} \sim 3.2$, in line the results presented here. 


\section{Conclusions}

At ASDEX Upgrade, H-modes with low magnetic shear in the centre achieve $\mathrm{H}_{98(\mathrm{y}, 2)}>1$ and $\beta$ ${ }_{N}=2-3$. The central tungsten concentration can be kept at acceptable levels $\left(<10^{-4}\right)$ in these experiments, provided ICRF and/or ECRF heating in the core is used to control impurity accumulation. Operation at high density with $<\mathrm{n}_{\mathrm{e}}>=1.1 \times 10^{20} \mathrm{~m}^{-3}\left(<\mathrm{n}_{\mathrm{e}}>/ \mathrm{n}_{\mathrm{GW}}=0.85-0.9\right)$ is demonstrated. However, the highest $\mathrm{H}_{98(\mathrm{y}, 2)}$ values are achieved at ITER relevant $v^{*}$ (operation at low $\left\langle\mathrm{n}_{\mathrm{e}}\right\rangle$ in ASDEX Upgrade). Improved H-modes at $\mathrm{q}_{95}=3.1$ achieve $\mathrm{H}_{98(\mathrm{y}, 2)}=1.4$ at $\beta_{\mathrm{N}}=2.9$, with fishbone activity in the centre keeping the q-profile stationary with $q(0) \sim 1$. ECCD can be used to stabilise $(3,2)$ NTM activity during the low beta $\left(\beta_{\mathrm{N}} \sim 2\right)$ phase of these discharges. The kinetic profile shapes at ASDEX Upgrade are scaled to ITER, setting $<\mathrm{n}_{\mathrm{e}}>=0.85 \mathrm{n}_{\mathrm{GW}}$ and maintaining the same value of $\beta_{\mathrm{N}, \text { th }}$. This predicts high fusion power for improved H-mode discharges at $\mathrm{q}_{95}=3.1\left(\mathrm{P}_{\text {fus }}=1070 \mathrm{MW}, \mathrm{Q}=\infty\right)$. In these conditions, the density and temperature at the edge are within ITER design parameters. At lower $\mathrm{I}_{\mathrm{p}}$ in ITER (9.5MA-13MA), significant fusion power can be achieved ( $\left.\mathrm{P}_{\text {fus }} \geq 400 \mathrm{MW}, \mathrm{Q}=6-15\right)$. However, using the IPB98 $(y, 2)$ scaling expression, the auxiliary power requirements at high $\beta_{\mathrm{N}}>2.5$ and at $\mathrm{I}_{\mathrm{p}}<11 \mathrm{MA}$ may exceed the maximum $\mathrm{P}_{\text {aux }}$ planned for the first stage of ITER (73 MW). 


\section{References}

[1] KIKUCHI, M., Nucl. Fusion 30 (1990) 265

[2] WAGNER, F., et al., Phys. Rev. Lett. 49 (1982) 1408

[3] ITER Physics Basis, Nucl. Fusion 39 (1999) 2175

[4] SHIMOMURA, Y., Plasma Phys. Control. Fusion 43 (2001) 385

[5] GREENWALD, M., et al., Nucl. Fusion, 28 (1988) 2199

[6] SHIMADA, M., et al., Nucl. Fusion 44 (2004) 350

[7] MUKHOVATOV, V., et al., Nucl. Fusion 43 (2003) 942

[8] PPCS, Power Plant Conceptual Study, EFDA report (September 2004) STAC 10/4.1

[9] KAMADA, Y., et al., Nucl. Fusion 34 (1994) 1605

[10] WOLF, R.C., et al., Plasma Phys. Control. Fusion 83 (1999) B93

[11] WADE, M.R., et al., 29th EPS Conference (Montreux, 2002), O2.08

[12] GRUBER, O., et al., Phys. Rev. Lett. 83 (1999) 1787

[13] SIPS, A.C.C., et al., Plasma Phys. Control. Fusion 44 (2002) B69

[14] PEETERS, A.G., et al., Nucl. Fusion 42 (2002) 1376

[15] STÄBLER, A., et al., Nucl. Fusion 45 (2005) 617

[16] GRUBER, O., et al., Plasma Phys. Control. Fusion 47 (2005) B135

[17] LUCE, T.C., et al., Nucl. Fusion 45 (2005) S86

[18] IDE, S., et al., Nucl. Fusion 45 (2005) S48

[19] JOFFRIN, E., et al., Nucl. Fusion 45 (2005) 626

[20] STOBER, J.K., et al., "Physics studies of the improved H-mode scenario in ASDEX Upgrade", submitted to Nucl. Fusion (2007)

[21] Mc CARTHY, P.J., Phys. Plasmas 6 (1999) 3554

[22] WOLF, R.C., et al., Europhysics Conference Abstracts (Proc. 24th Eur. Conf. Berchtesgaden 1997), 21A, (1997) 1509

[23] NA, Y.-S., et al., Nucl. Fusion 46 (2006) 232

[24] MAGGI, C. F., et al., Nucl. Fusion 47 (2007) 535

[25] STOBER, J., et al., Plasma Phys. Control. Fusion 42 (2000) A211

[26] SAIBENE, G., et al., Plasma Phys. Control. Fusion 44 (2002) 1769

[27] NEU, R., et al., Journal of Nuclear Materials 363-365 (2007) 52 
[28] BOBKOV, V.V., et al., Journal of Nuclear Materials 363-365 (2007) 122

[29] MARASCHEK, M., et al., Plasma Phys. Control. Fusion 41 (1999) L1

[30] PEREVERZEV, G.V., et al., IPP Report (1991) 5/42

[31] ZOHM, H., et al., Nucl. Fusion 47 (2007) 228

[32] TARDINI, G., et al., 33 ${ }^{\text {rd }}$ EPS Conference Rome (19-23 June 2006), P.112

[33] LUCE, T.C., et al., Phys. Plasmas 11 (2004) 2627

[34] WEISEN, H., et al., Plasma Phys. Control. Fusion 48 (2006) A457

[35] ANGIONI, C., et al., Phys. Rev. Lett. 90 (2003) 205003

[36] SUGIHARA, M., et al., Plasma Phys. Control. Fusion 45 (2003) L55

[37] PETTY, G., et al., Fusion Sci. Technol. 43 (2003) 1

[38] CORDEY, J.G., et al., Nucl. Fusion 45 (2005) 1078

[39] PEETERS, A.G., et al., "On the extrapolation to ITER of discharges in present tokamaks", submitted to Nucl. Fusion arXiv:physics/0701185v1 (2007)

[40] WADE, M.R., et al., Nucl. Fusion 45 (2005) 407 


\section{Tables}

Table I: Overview of discharges used in the Type I ELMy H-mode dataset and the improved $H$-mode dataset at ASDEX Upgrade. The number of time-slices in the dataset is given (\#). Ranges are given for the edge safety factor $\left(q_{95}\right)$, the line-averaged electron density $\left(\left\langle n_{e}\right\rangle\right)$, the fraction of the Greenwald density limit $\left(<n_{e}>n_{G W}\right)$, the confinement enhancement factor $H_{98(y, 2)}$, the normalised beta $\left(\beta_{N}\right)$ and the plasma inductance $\left(l_{i}\right)$. The values in brackets are average values.

\begin{tabular}{|l|c|c|c|c|c|c|c|}
\hline dataset & $\#$ & $\mathbf{q}_{\mathbf{9 5}}$ & $\begin{array}{c}<\mathbf{n}_{\mathbf{e}}> \\
\left(\mathbf{x 1 0} \mathbf{1 9}^{\mathbf{2}}\right)\end{array}$ & $<\mathbf{n}_{\mathbf{e}}>/ \mathbf{n}_{\mathbf{G W}}$ & $\mathbf{H}_{\mathbf{9 8}(\mathbf{y}, \mathbf{2})}$ & $\boldsymbol{\beta}_{\mathbf{N}}$ & $\mathbf{I}_{\mathbf{i}}$ \\
\hline $\begin{array}{l}\text { Type I } \\
\text { ELMy } \\
\text { H-modes }\end{array}$ & 944 & $\begin{array}{c}2.9-5.5 \\
(4.1)\end{array}$ & $\begin{array}{c}2.6-14 \\
(7.0)\end{array}$ & $\begin{array}{c}0.25-1.1 \\
(0.60)\end{array}$ & $\begin{array}{c}0.5-1.6 \\
(1.08)\end{array}$ & $\begin{array}{c}0.7-3.5 \\
(1.89)\end{array}$ & $\begin{array}{c}0.75-1.3 \\
(0.95)\end{array}$ \\
$\begin{array}{l}\text { Improved } \\
\text { H-modes }\end{array}$ & 259 & $\begin{array}{c}2.8-5.4 \\
(4.0)\end{array}$ & $\begin{array}{c}4.0-12 \\
(6.6)\end{array}$ & $\begin{array}{c}0.3-0.97 \\
(0.54)\end{array}$ & $\begin{array}{c}0.8-1.5 \\
(1.21)\end{array}$ & $\begin{array}{c}1.4-3.6 \\
(2.43)\end{array}$ & $\begin{array}{c}0.75-1.1 \\
(0.89)\end{array}$ \\
\hline
\end{tabular}

Table II: Overview of discharges at 1.0MA, q95 $_{95}$, with similar low $v^{*}$ and different confinement enhancement factors.

\begin{tabular}{|c|c|c|c|c|c|c|c|}
\hline$\#$ & $\mathbf{V}^{*} / \mathbf{V}^{*}{ }_{\text {ITER }}$ & $\mathbf{H}_{\mathbf{9 8}(\mathbf{y}, \mathbf{2})}$ & $\mathbf{q}_{\mathbf{9 5}}$ & $\mathbf{I}_{\mathbf{p}}[\mathbf{M A}]$ & $\mathbf{B}_{\mathbf{T}}[\mathbf{T}]$ & $\mathbf{P}_{\text {add }}[\mathbf{M W}]$ & Behaviour \\
\hline $\mathbf{1 6 6 8 8}$ & 2.3 & 1.45 & 4.0 & 1.0 & 2.1 & 9.2 & fishbones \\
$\mathbf{1 7 5 1 9}$ & 2.9 & 1.44 & 3.8 & 1.0 & 2.0 & 5.7 & fishbones \\
$\mathbf{1 6 7 3 6}$ & 2.8 & 1.40 & 4.0 & 1.0 & 2.1 & 9.5 & fishbones \\
$\mathbf{1 7 5 1 1}$ & 2.4 & 1.40 & 3.8 & 1.0 & 2.0 & 6.8 & fishbones \\
$\mathbf{1 7 2 9 6}$ & 2.6 & 1.36 & 3.8 & 1.0 & 2.0 & 6.5 & fishbones \\
$\mathbf{2 0 0 0 5}$ & 2.5 & 1.21 & 4.1 & 1.0 & 2.4 & 10.0 & fishbones $+(3,2)$ \\
$\mathbf{1 8 8 8 0}$ & 2.8 & 1.17 & 4.0 & 1.0 & 2.2 & 12.5 & NTM \\
$\mathbf{1 8 8 8 1}$ & 2.4 & 1.10 & 4.1 & 1.0 & 2.2 & 13.0 & $(3,2) \mathrm{NTM}$ \\
$\mathbf{1 8 0 4 6}$ & 2.7 & 1.06 & 3.8 & 1.0 & 2.1 & 5.0 & low power \\
$\mathbf{1 8 8 6 9}$ & 2.9 & 1.01 & 3.9 & 1.0 & 2.2 & 8.8 & Strong $(3 / 2)$ \\
\hline
\end{tabular}


Table III: Overview of four specific ASDEX Upgrade pulses and the extrapolation to ITER, using the assumption given in the text.

\begin{tabular}{|c|c|c|c|c|c|c|c|c|}
\hline & $\begin{array}{c}\text { AUG, } \\
\# 17847\end{array}$ & ITER & $\begin{array}{c}\text { AUG, } \\
\# 20449\end{array}$ & ITER & $\begin{array}{c}\text { AUG, } \\
\# 17870\end{array}$ & ITER & $\begin{array}{c}\text { AUG, } \\
\# 20448\end{array}$ & ITER \\
\hline Type & $\begin{array}{l}\text { Standard } \\
\text { H-mode }\end{array}$ & & $\begin{array}{c}\text { Improve } \\
d \mathrm{H}- \\
\text { mode }\end{array}$ & & $\begin{array}{c}\text { Improve } \\
d H- \\
\text { mode }\end{array}$ & & $\begin{array}{c}\text { Improve } \\
d \mathrm{H}- \\
\text { mode }\end{array}$ & \\
\hline $\mathbf{I}_{\mathrm{p}}$ (MA) & 1.15 & 14.7 & 1.2 & 14.2 & 1.0 & 11.8 & 1.0 & 9.7 \\
\hline $\mathbf{B}_{\mathrm{T}}$ (Tesla) & 2.0 & 5.3 & 2.0 & 5.3 & 2.1 & 5.3 & 2.4 & 5.3 \\
\hline $\mathbf{q}_{95}$ & 3.05 & 3.05 & 3.17 & 3.17 & 3.8 & 3.8 & 4.6 & 4.6 \\
\hline$n_{\mathrm{e} 0}\left(10^{19} \mathrm{~m}^{-3}\right)$ & 12.0 & 11.2 & 8.1 & 12.2 & 8.0 & 12.6 & 8.5 & 9.4 \\
\hline$<n_{e}>\left(10^{19} m^{-3}\right)$ & 10.6 & 9.9 & 6.3 & 9.6 & 5.1 & 8.0 & 5.9 & 6.6 \\
\hline$<\mathbf{n}_{\mathbf{e}}>/ \mathbf{n}_{\mathbf{G W}}$ & 0.73 & 0.85 & 0.41 & 0.85 & 0.40 & 0.85 & 0.46 & 0.85 \\
\hline$\beta_{\mathrm{N}, \text { th }}$ & 1.94 & 1.94 & 2.80 & 2.80 & 2.40 & 2.40 & 2.22 & 2.22 \\
\hline $\mathbf{H}_{98(\mathrm{y}, 2)}$ & 0.95 & 0.95 & 1.40 & 1.40 & 1.32 & 1.32 & 1.44 & 1.44 \\
\hline $\mathrm{T}_{\mathrm{e} 0}(\mathrm{keV})$ & 2.4 & 20.3 & 4.7 & 29.5 . & 4.0 & 28.2 & 5.7 & 27.4 \\
\hline $\mathrm{T}_{\mathrm{i} 0}(\mathrm{keV})$ & 1.8 & 20.3 & 6.9 & 29.5 & 7.1 & 28.2 & 6.3 & 27.4 \\
\hline $\mathbf{Q}$ & - & 8.0 & - & $\infty$ & - & 11.4 & - & 6.5 \\
\hline$P_{\text {fus }}(\mathbf{M W})$ & - & 619 & - & 1070 & - & 597 & - & 360 \\
\hline$P_{\text {aux }}(\mathrm{MW})$ & 7.7 & 78 & 8.3 & 0 & 7.5 & 52 & 11.0 & 55 \\
\hline
\end{tabular}




\section{Figures}

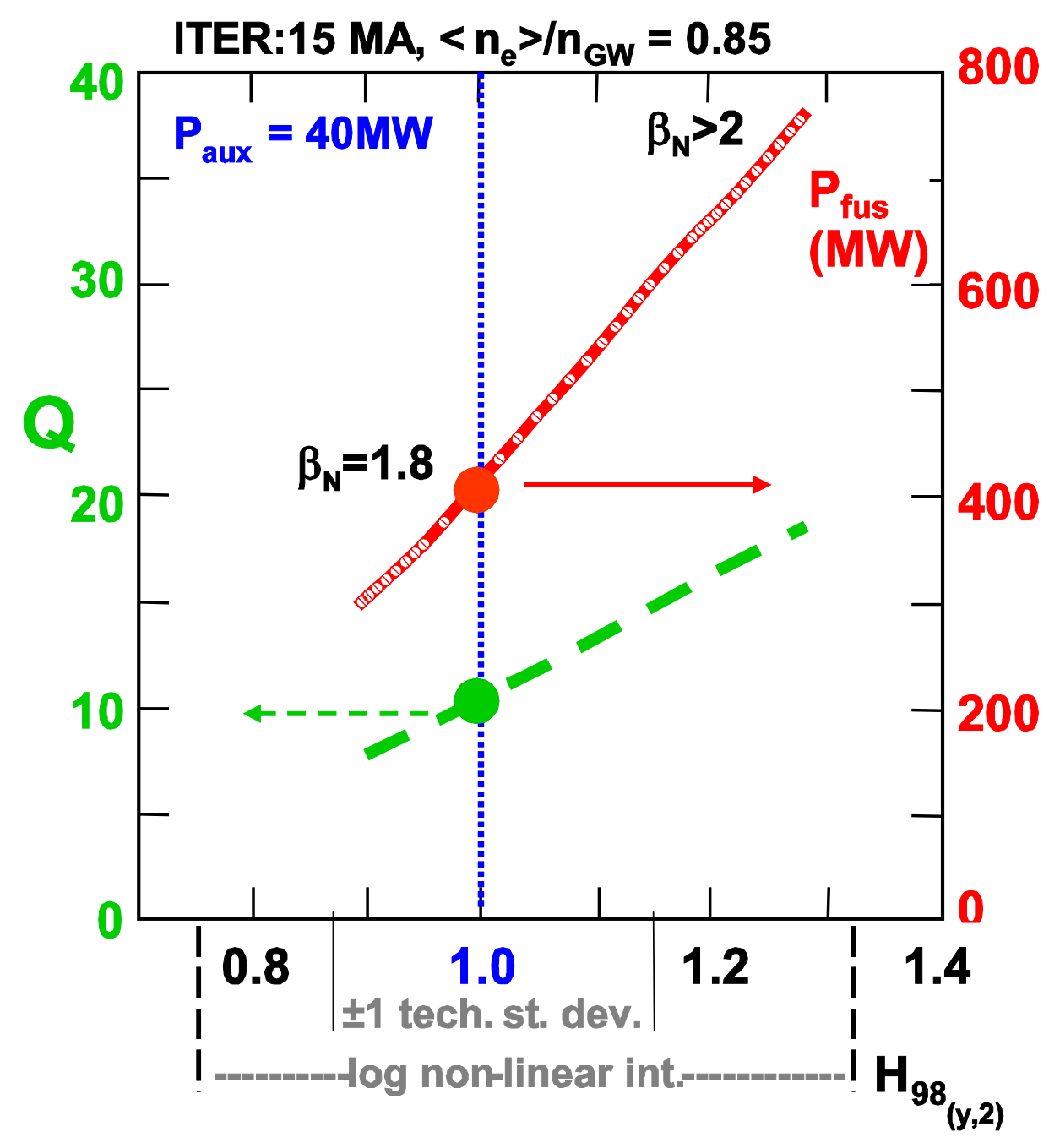

Figure 1: Simulation of the ITER reference scenario as given in Figure 1 of reference [7]. The prediction (points in this graphs) of the fusion power ( $P_{\text {fus }}$, right $y$-axis) and fusion gain $\left(Q\right.$, left $y$-axis) are given for ITER at 15MA, 5.3T, $<n_{e}>/ n_{G W}=0.85$ and $40 M W$ of input power. The variation of the ITER performance ( $P_{\text {fus }}$, solid curve, and $Q$ dashed curve) shows a strong dependence of $P_{f u s}$ and $Q$ on $H_{98(y, 2)}$. The confidence interval for the IPB98(y,2) scaling expression is also specified. 


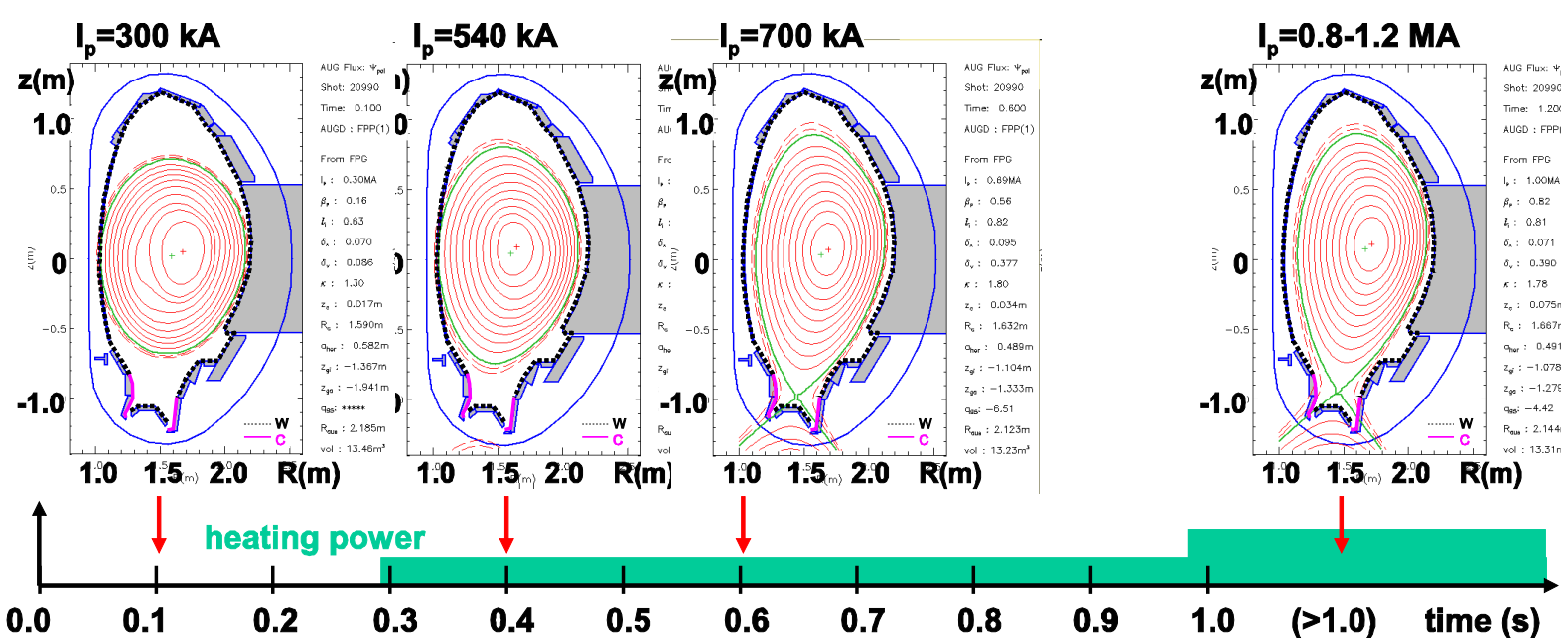

Figure 2: Evolution of the plasma cross section during the current rise phase of an improved H-mode at ASDEX Upgrade. Typically 2.5MW of neutral beam heating is applied during the current rise $(t<1.0 \mathrm{~s})$, followed by an increase in heating during the flattop phase (with $\left.I_{p}=0.8-1.2 M A\right)$. The first wall components covered with tungsten coated carbon tiles are indicated by the black, dotted lines, the areas covered with carbon tiles indicated by the solid purple lines (lower divertor). 


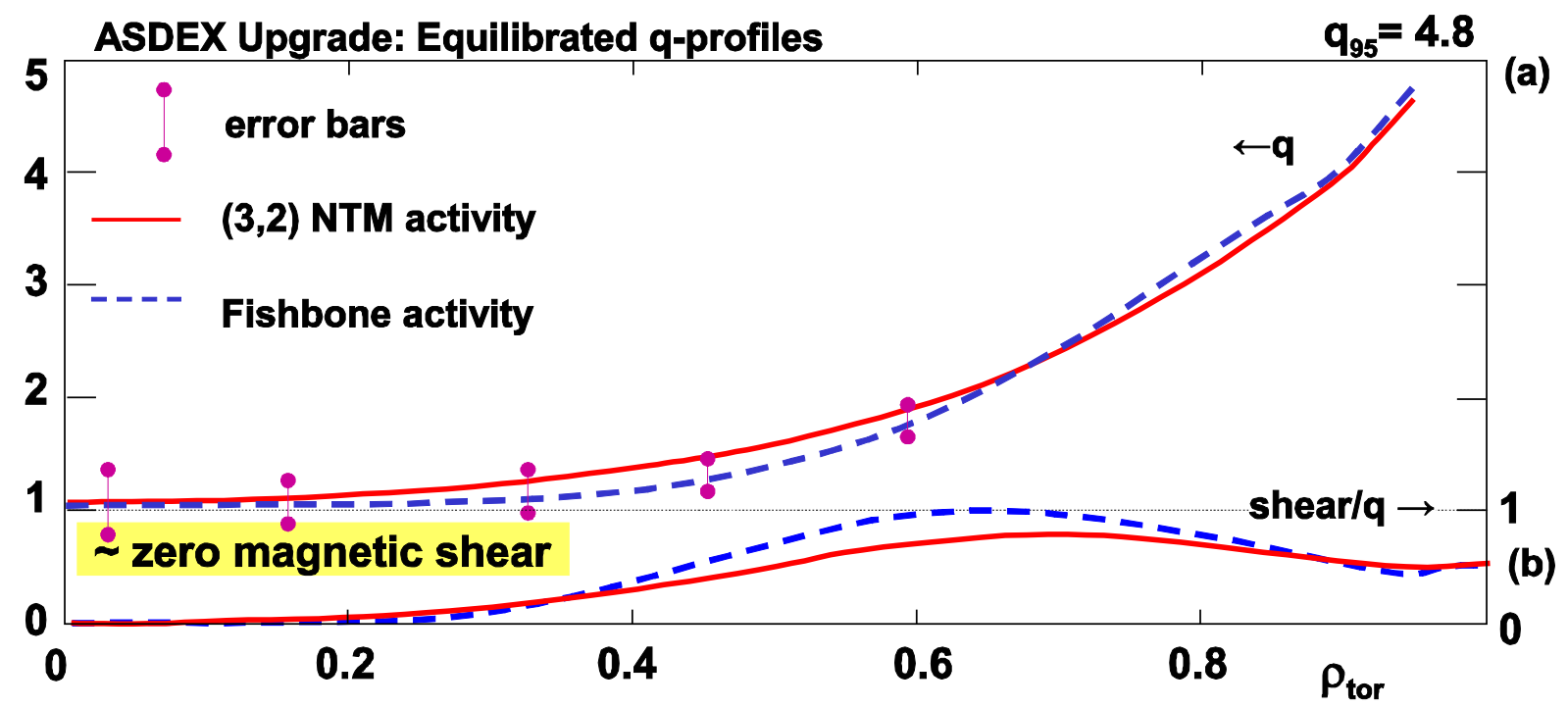

Figure 3: Typical q-profiles in improved H-modes for two types [20] of discharges. These qprofiles are obtained during the flat top phase of the pulse. (a) One discharge with NTM activity (solid curve) is compared to one discharge with fishbone activity in the centre (dashed curve), (b) The magnetic shear $s=(r / q) d q / d r$ is shown, normalised to the local $q$ value for these two cases. 


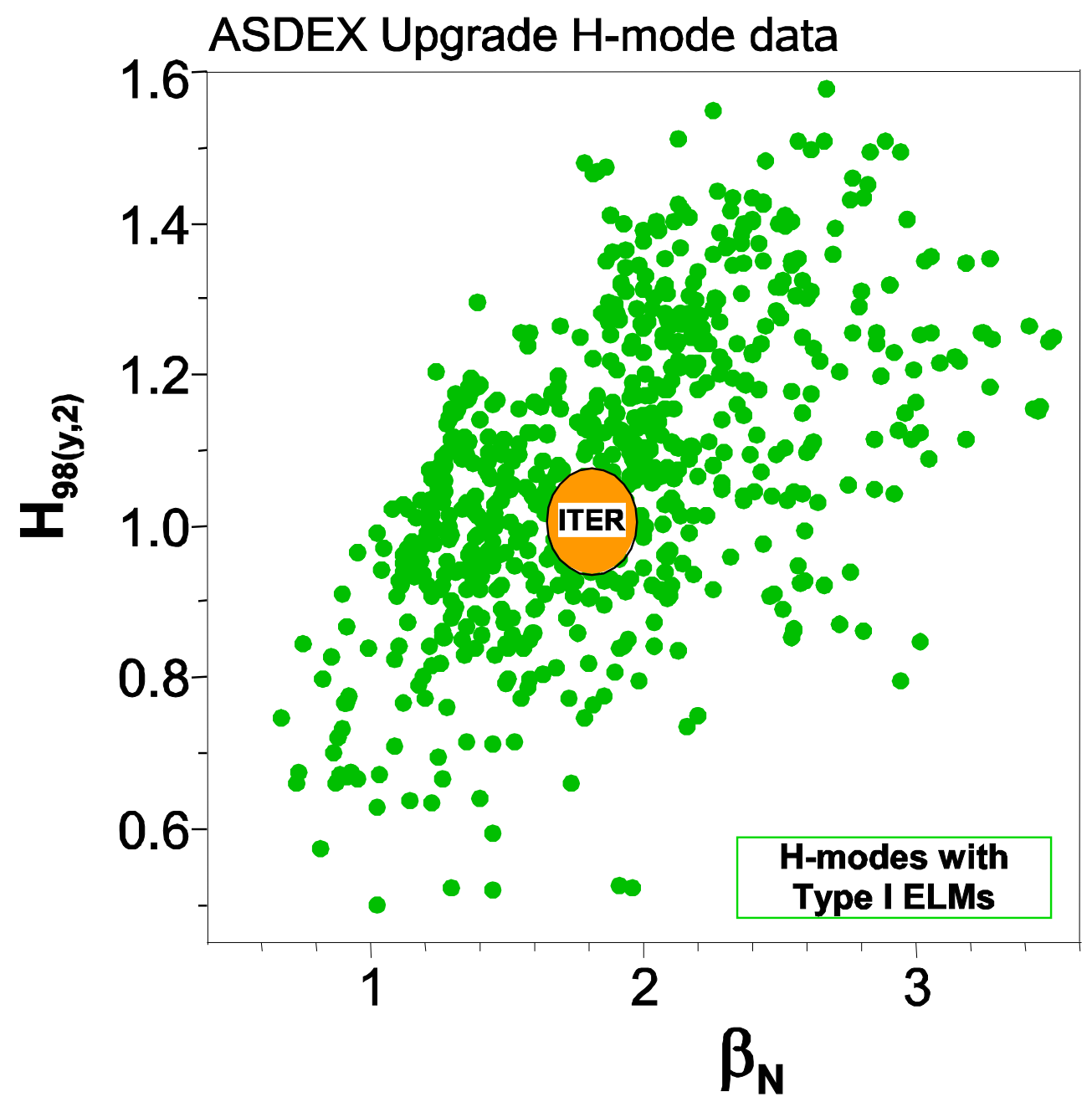

Figure 4a: Overview of Type I ELMy H-modes in ASDEX Upgrade. As given in Table I, a wide range of $H_{98}(y, 2$,$) and \beta_{N}$ is obtained. Also indicated are the values for the ITER reference scenario. 


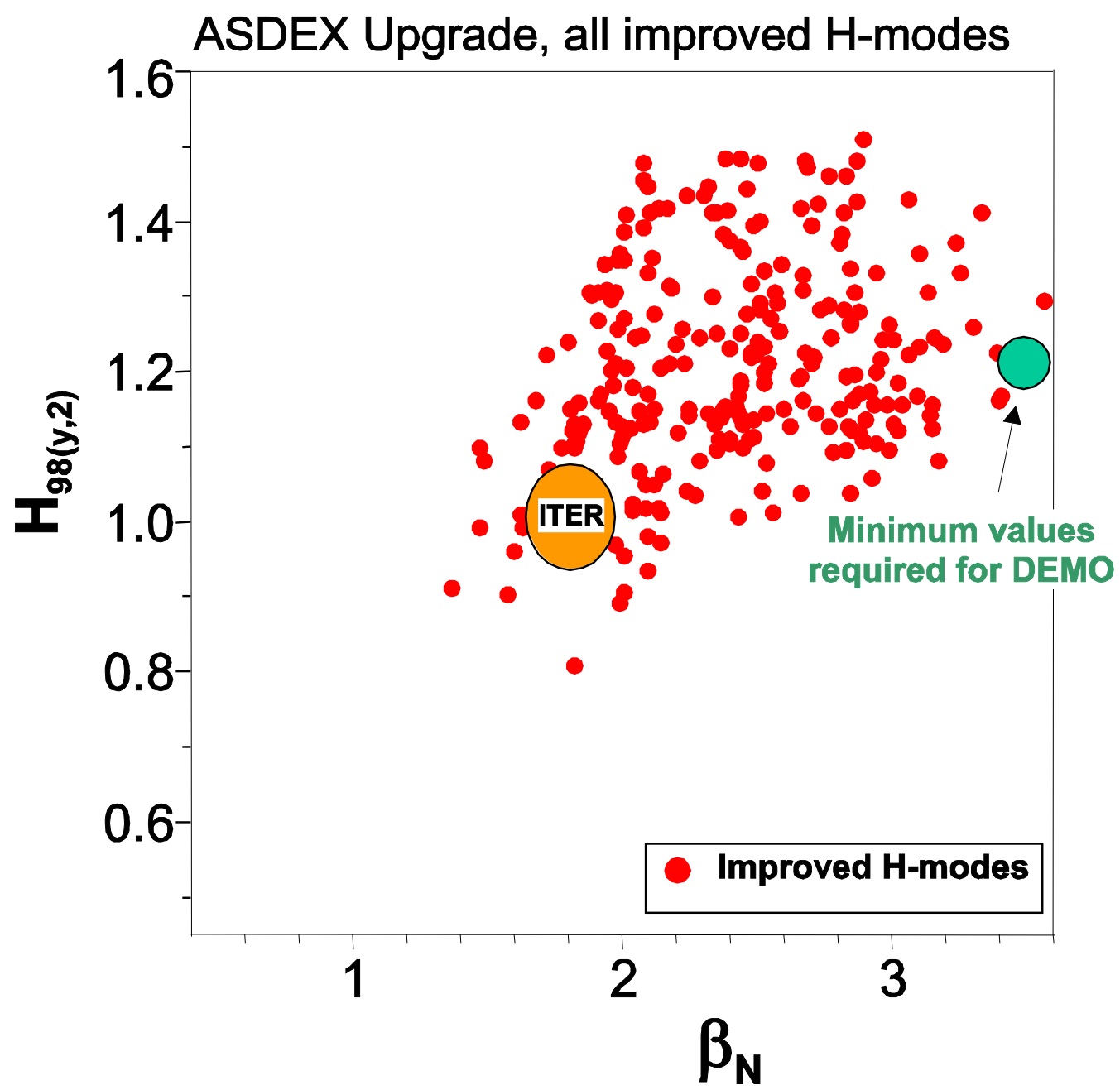

Figure 4b: Overview of improved H-mode discharges in ASDEX Upgrade. As given in Table I, most pulses obtain $H_{98}(y, 2)>$,1 and $\beta_{N}>2$. Also indicated are the values for the ITER reference scenario, and the minimum values required for a DEMO reactor [8]. 


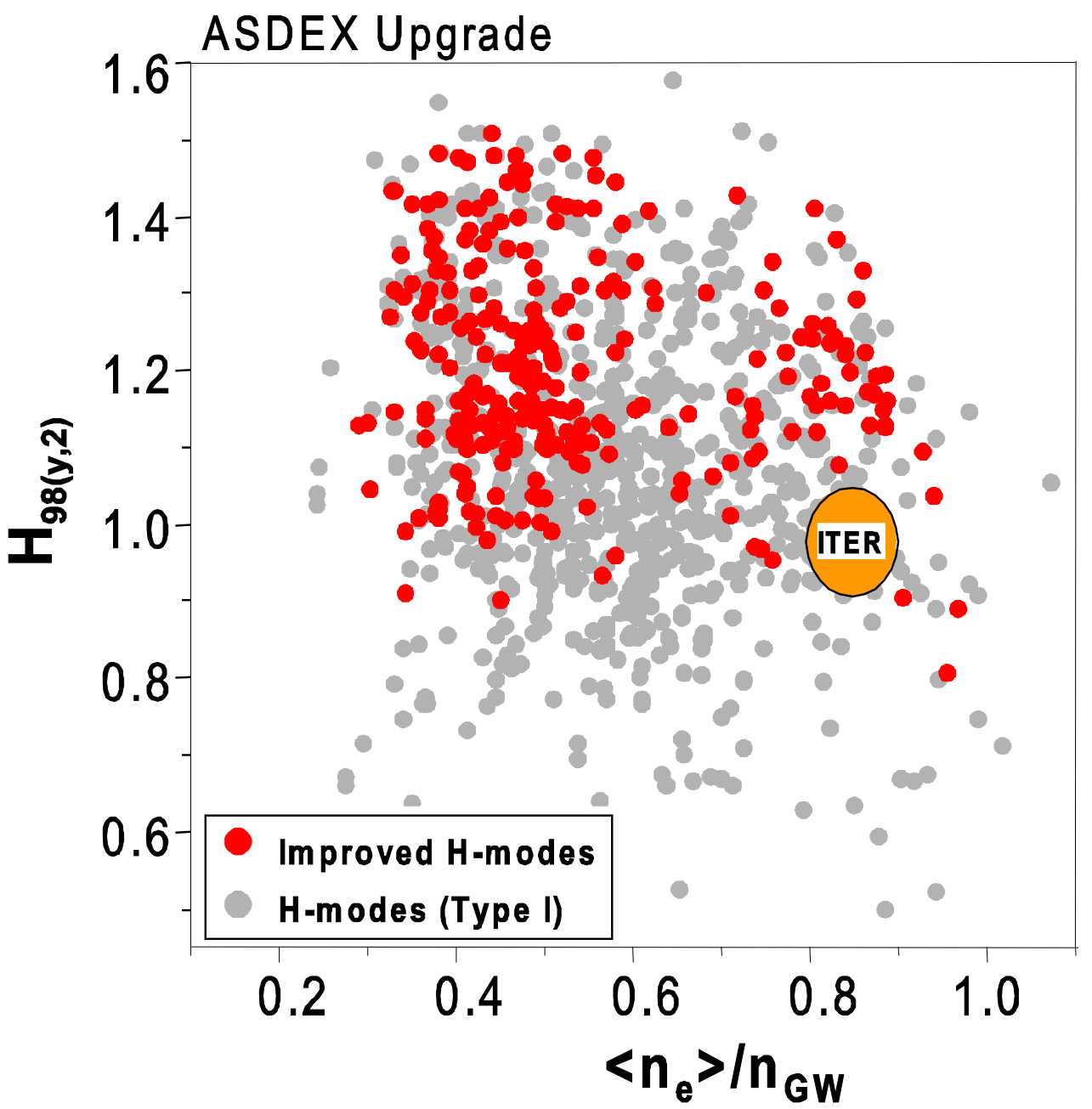

Figure 5: H-mode operation at ASDEX Upgrade showing the $H_{98(y, 2)}$ factors obtained for a range of line-averaged densities normalised to the Greenwald density limit $\left.\left(<n_{e}\right\rangle / n_{G W}\right)$. Data points are given for both datasets of Table I: The Type I ELMy H-mode dataset (grey) and the improved H-mode dataset (darker colour). Also indicated are the values for the ITER reference scenario. 


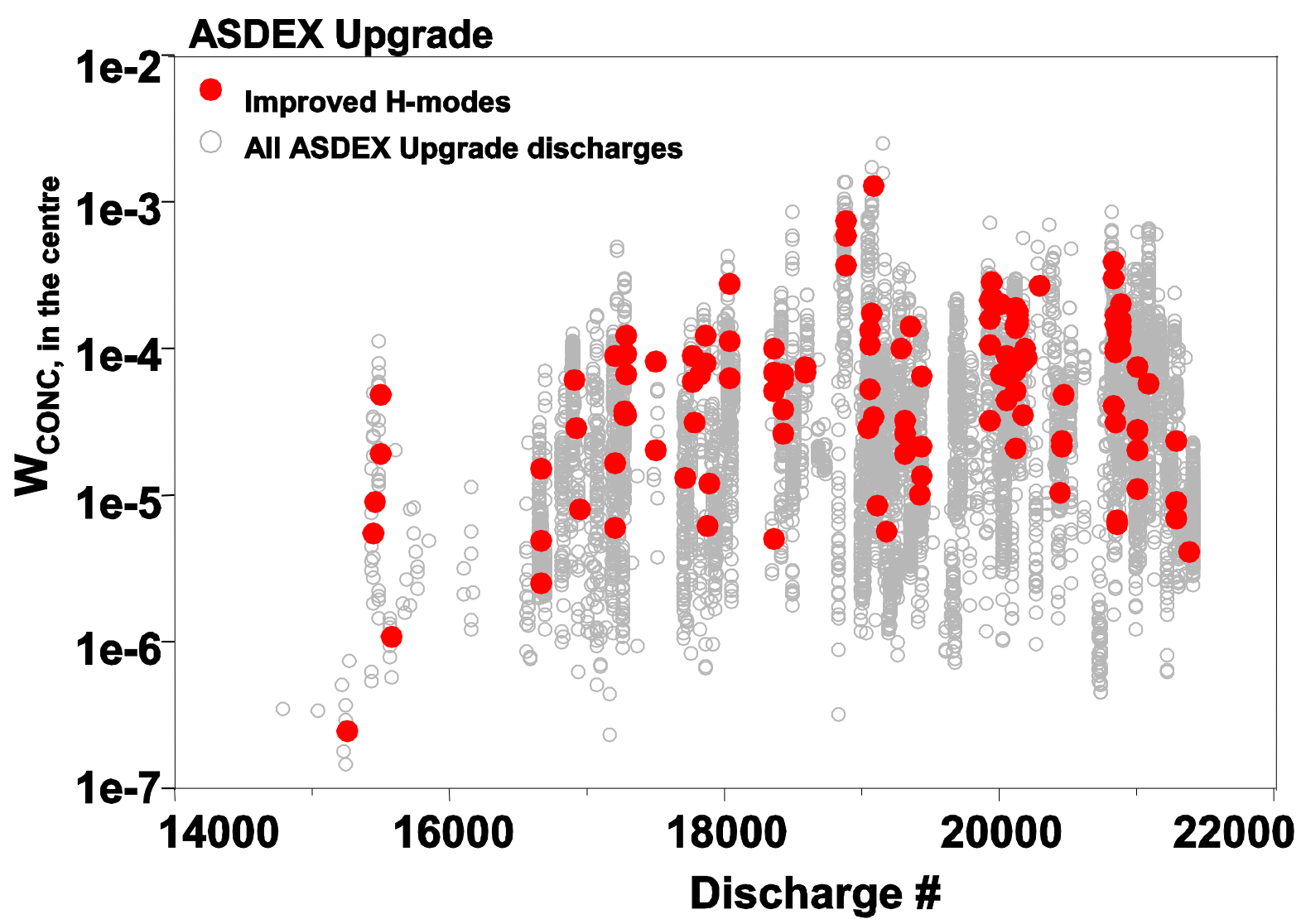

Figure 6: The concentration of tungsten in the centre for \# 14000 (March 2001) to \# 21500 (April 2006). Data points are given for two sets of data: All successful discharges in ASDEX Upgrade during this period (grey) and the improved H-mode data given in Table I (darker colour). 


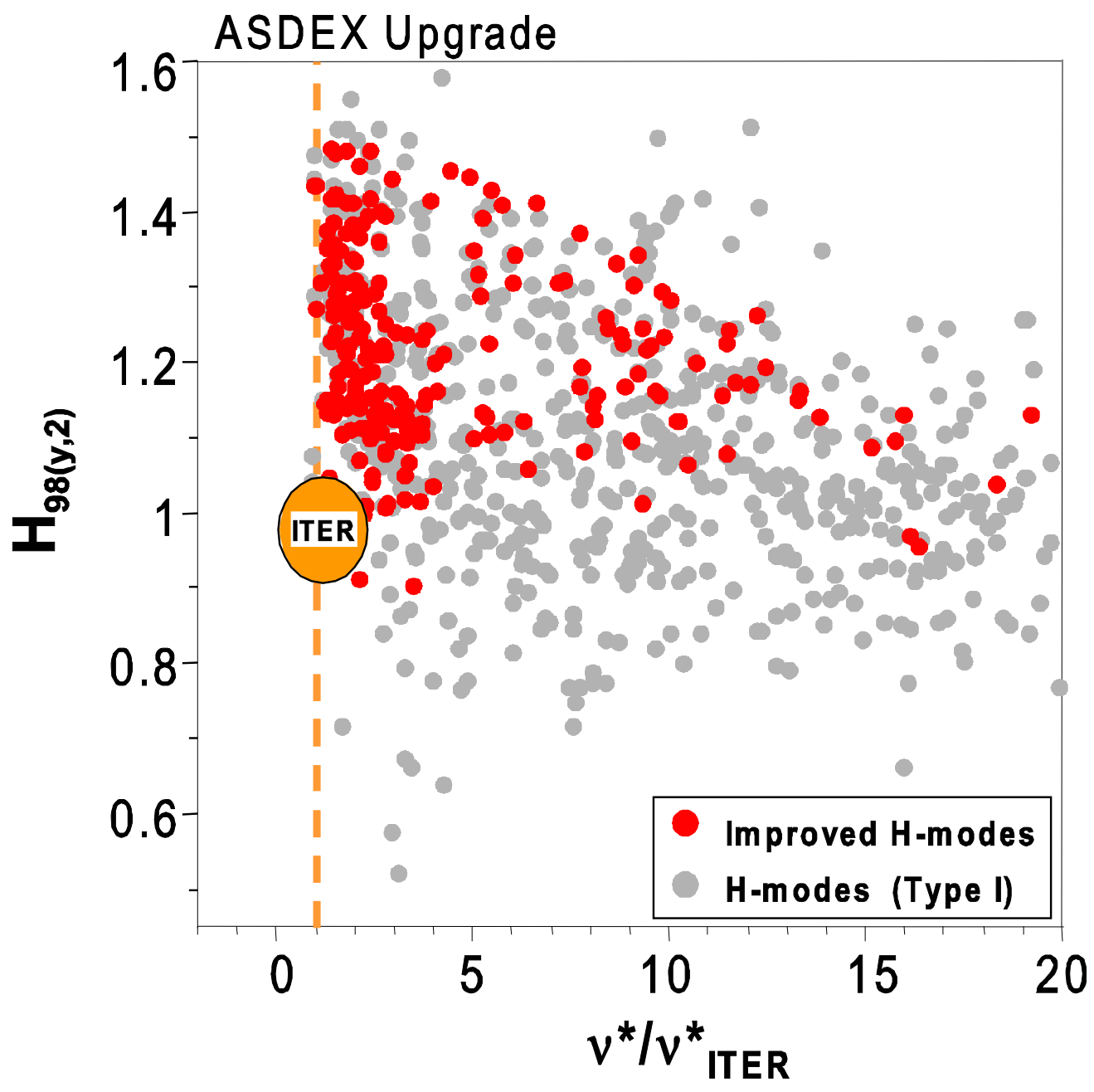

Figure 7: H-mode operation at ASDEX Upgrade showing the $H_{98(y, 2)}$ factors obtained for a range of collisionality, normalised to the ITER collisionality $\left(\nu * / \nu *_{\text {ITER }}\right)$. Data points are given for both datasets of Table I: The Type I ELMy H-mode dataset (grey) and the improved $H$-mode data set (darker colour). Also indicated are the values for the ITER reference scenario. 


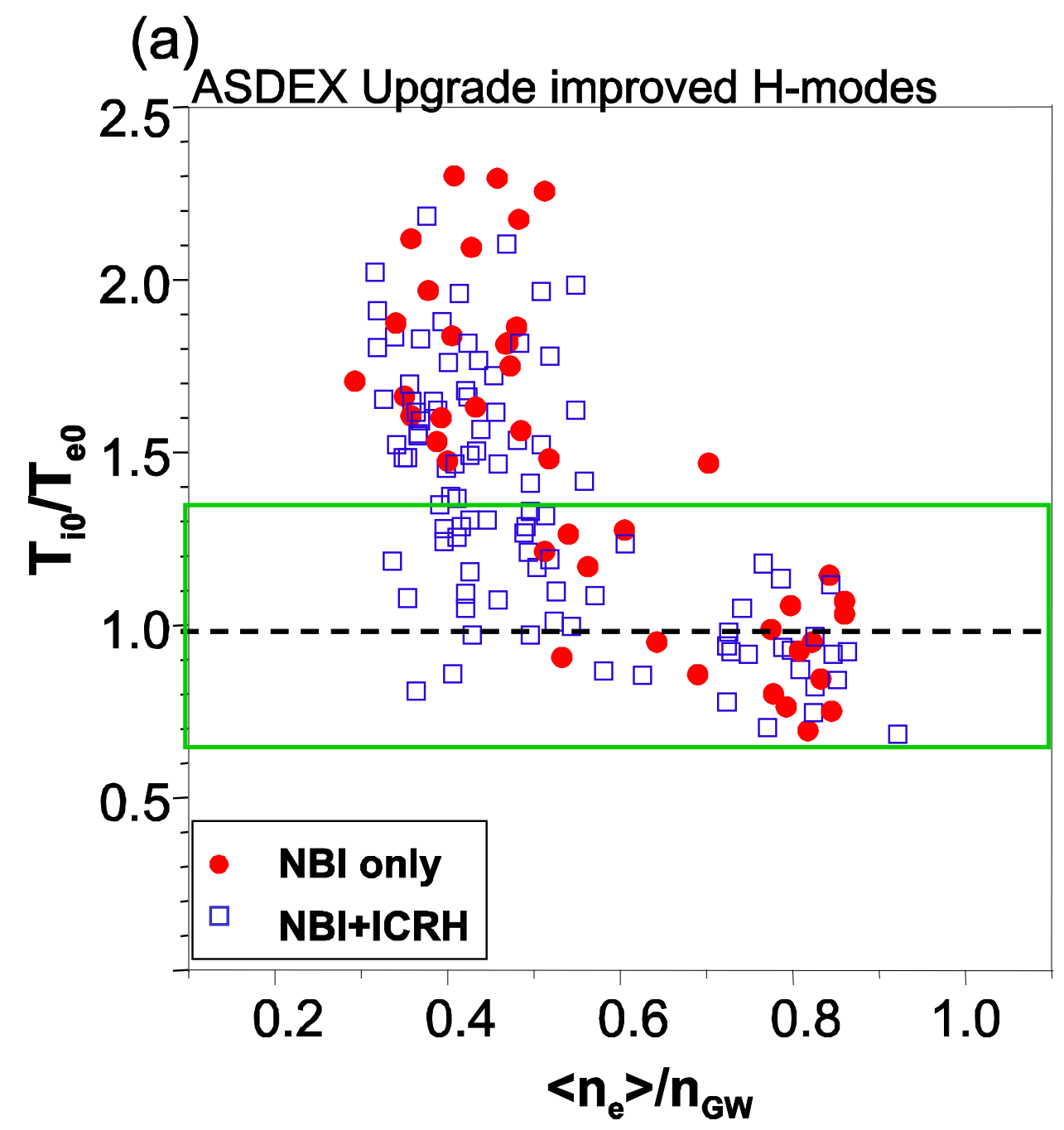

Figure 8a: For a set of improved H-mode discharges in ASDEX Upgrade, the ratio of the central ion temperature $\left(T_{i 0}\right)$ to the central electron temperature $\left(T_{e 0}\right)$ is given relative to the line-averaged density normalised to the Greenwald density limit $\left(<n_{e}>/ n_{G W}\right)$. The range $0.7<T_{i 0} / T_{e 0}<1.3$ is highlighted. Indicated are discharges that are heated with NBI alone (circles) and the discharges heated with a combination of NBI and ICRH (open squares). 


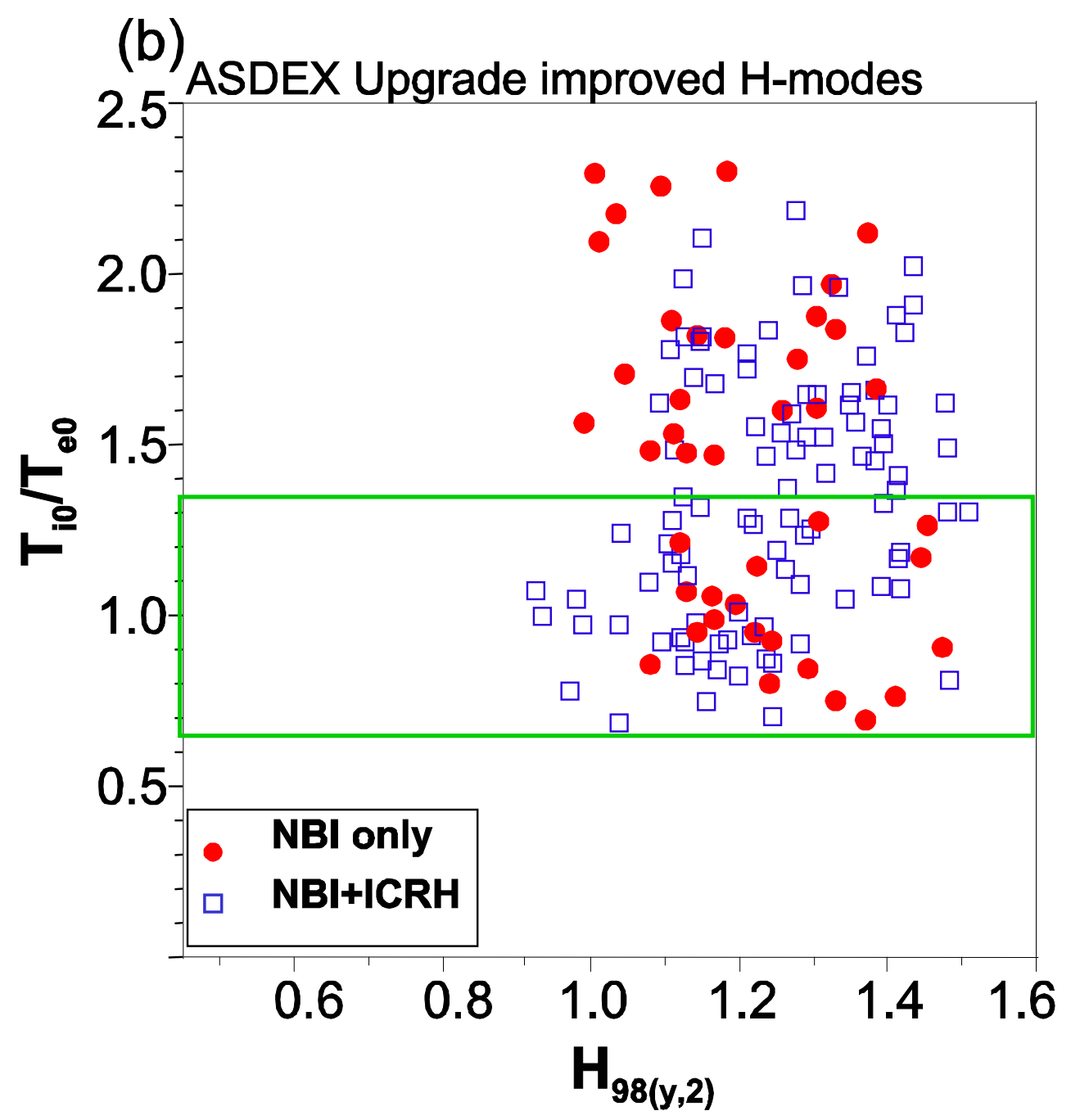

Figure 8b: For a set of improved H-mode discharges in ASDEX Upgrade, the ratio of the central ion temperature $\left(T_{i 0}\right)$ to the central electron temperature $\left(T_{e 0}\right)$ is given relative to the $H_{98(y, 2)}$ confinement enhancement factor. The range $0.7<T_{i 0} / T_{e 0}<1.3$ is highlighted. Indicated are discharges that are heated with NBI alone (circles) and the discharges heated with a combination of NBI and ICRH (open squares). 

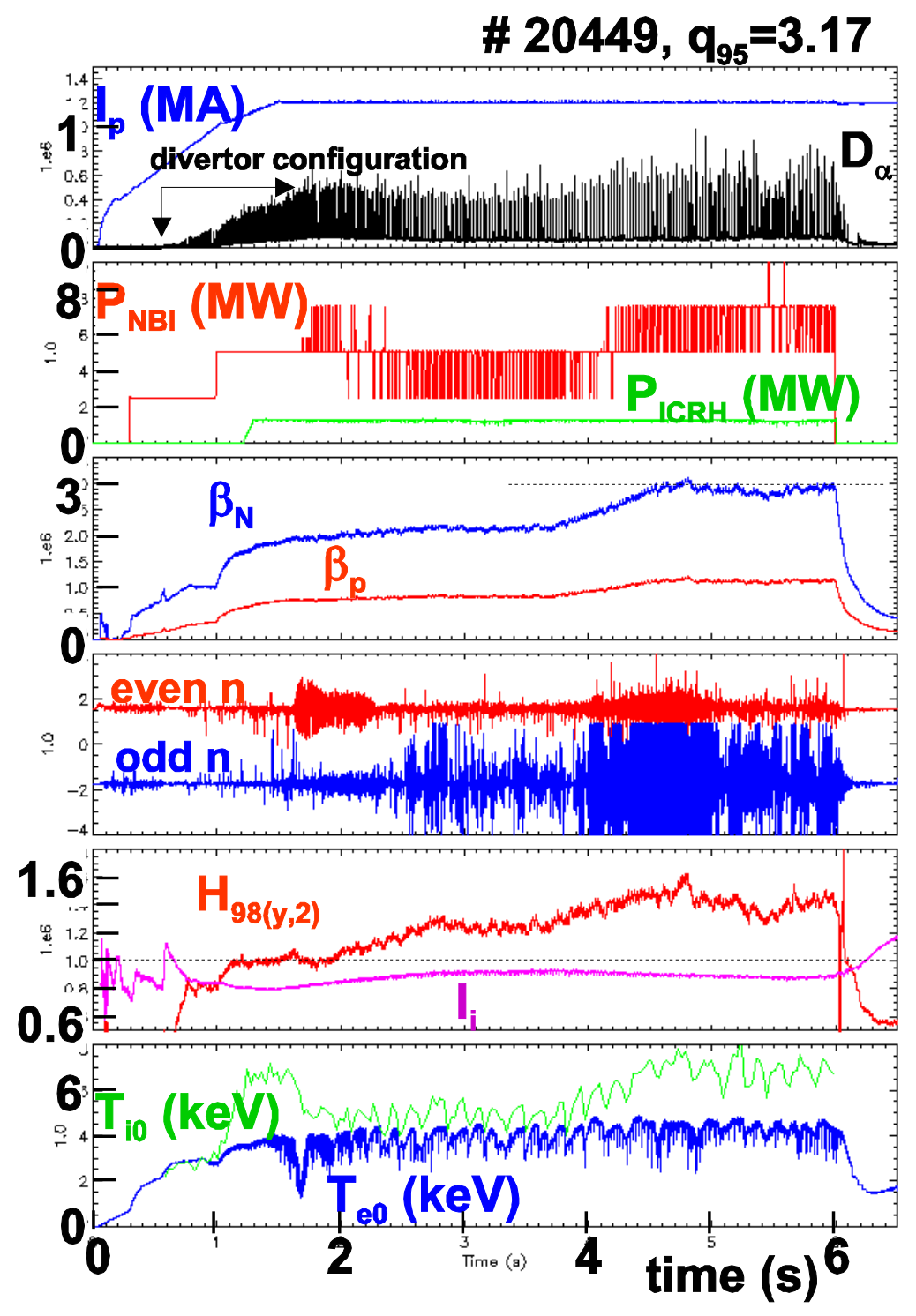

Figure 9: An improved H-mode at $q_{95}=3.17$ in ASDEX Upgrade (1.2MA/2.0T, \#20449). Shown are (from top to bottom): The plasma current $\left(I_{p}\right)$ and the $D_{\alpha}$ emission from the lower divertor, with an indication when the divertor configuration is formed, the neutral beam power $\left(P_{N B I}\right)$ and ion cyclotron resonance heating power $\left(P_{\text {ICRH }}\right)$ used, the poloidal beta $\left(\beta_{p}\right)$ and normalised beta $\left(\beta_{N}\right)$ achieved (a dotted line indicates $\beta_{N}=3$ ), the observed MHD activity for even and odd harmonic mode numbers, the confinement enhancement factor $H_{98(y, 2)}$ and the plasma inductance $\left(l_{i}\right)$ (a dotted line indicates $H_{98(y, 2)}=1$, or $l_{i}=1$ ), the central ion temperatures $\left(T_{i 0}\right)$ and central electron temperatures $\left(T_{e 0}\right)$ obtained. 


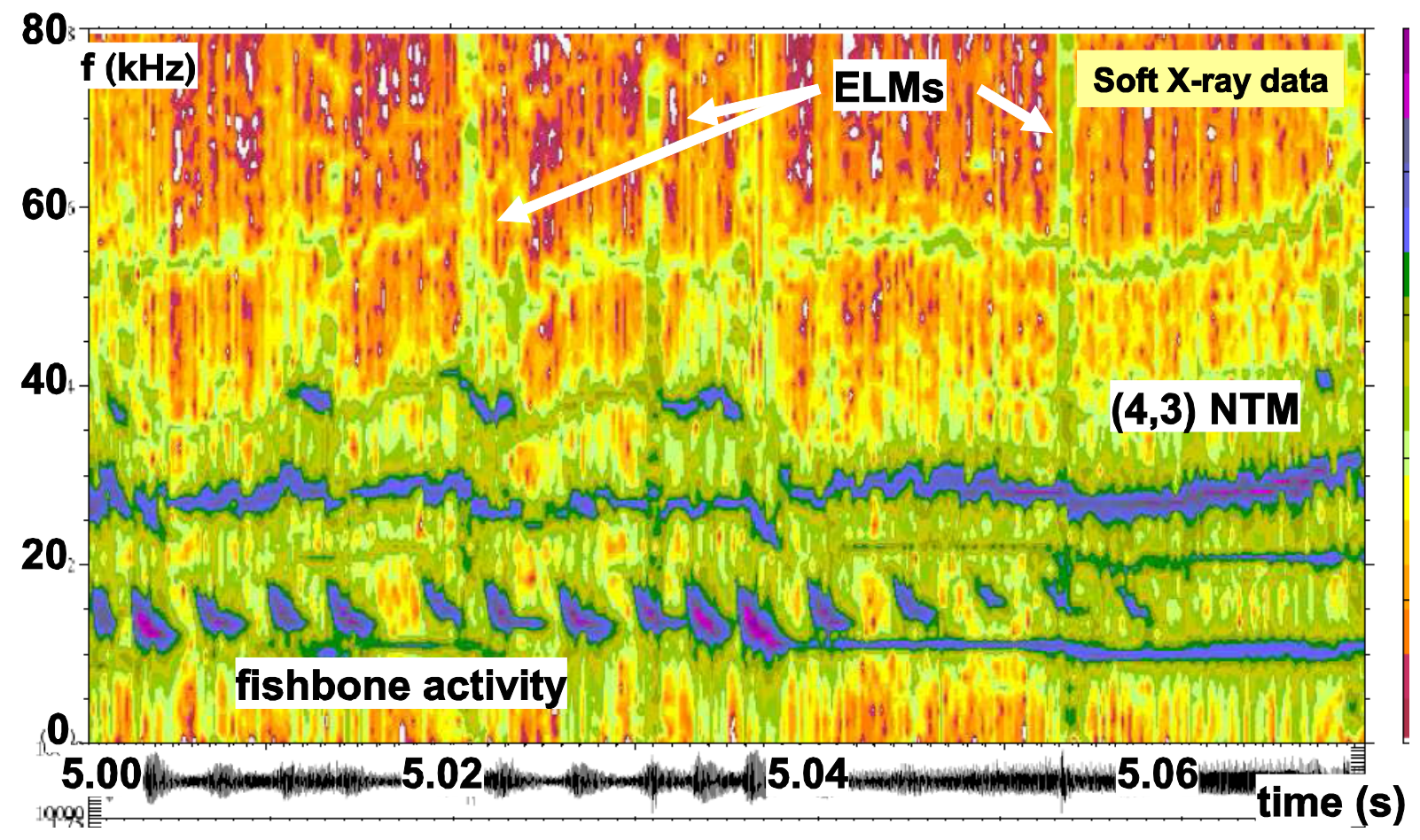

Figure 10: Fourier spectra of the MHD activity observed using soft X-ray data viewing the central region of the plasma for \#20449 (the discharge shown in Figure 9). 


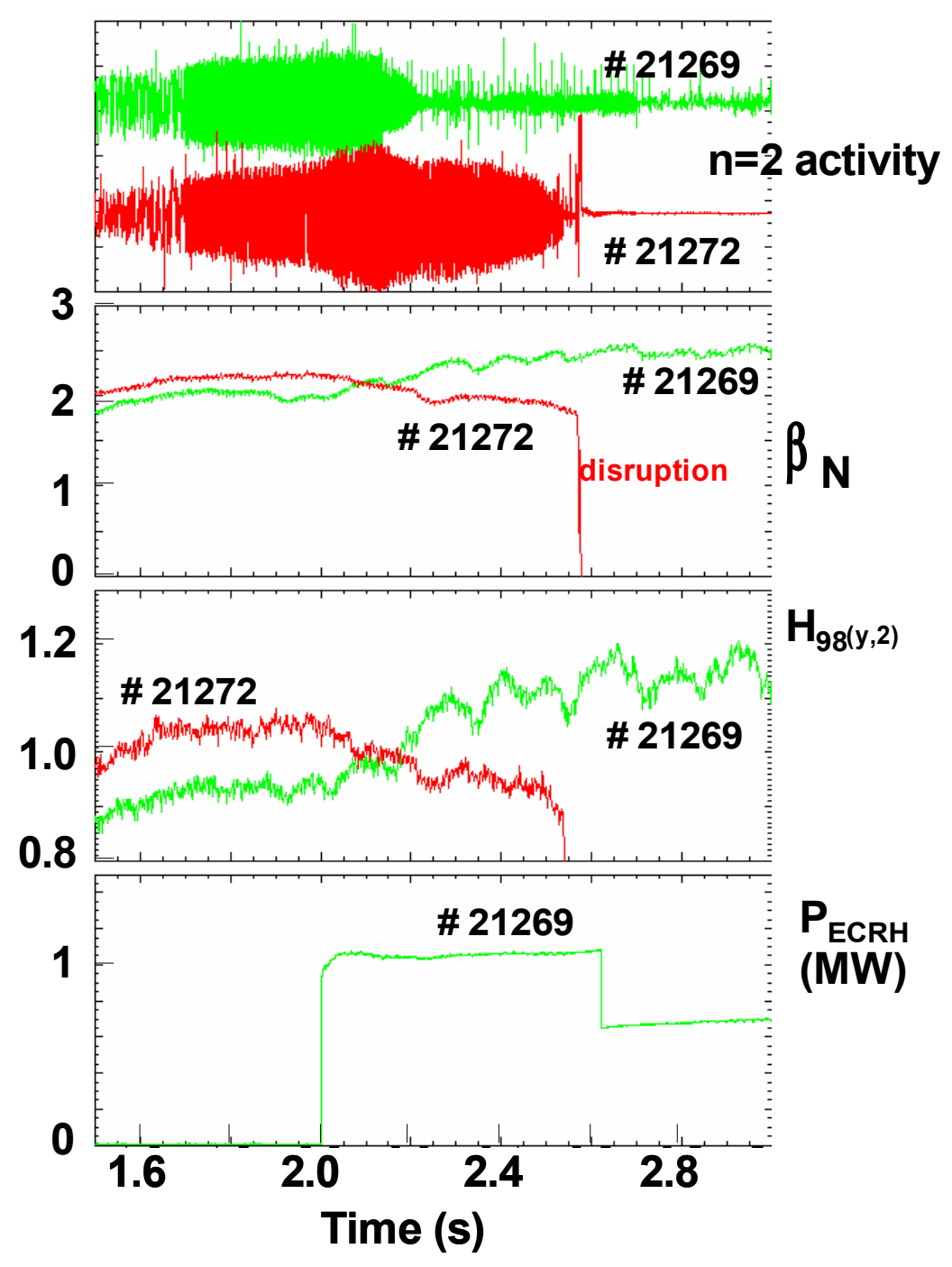

Figure 11: Two similar discharges at $q_{95}=3.17$ in ASDEX Upgrade (1.2MA/2.0T). \#21269 uses ECCD to stabilise the $(3,2)$ NTM, \#21272 does not. Shown are (from top to bottom): The observed MHD activity for the $n=2$ harmonic mode numbers (indicating the $(3,2)$ NTM activity), the normalised beta $\left(\beta_{N}\right)$ achieved, the confinement enhancement factor $H_{98(y, 2)}$ obtained and the electron cyclotron power applied $\left(P_{E C R H}\right)$. 
(a)

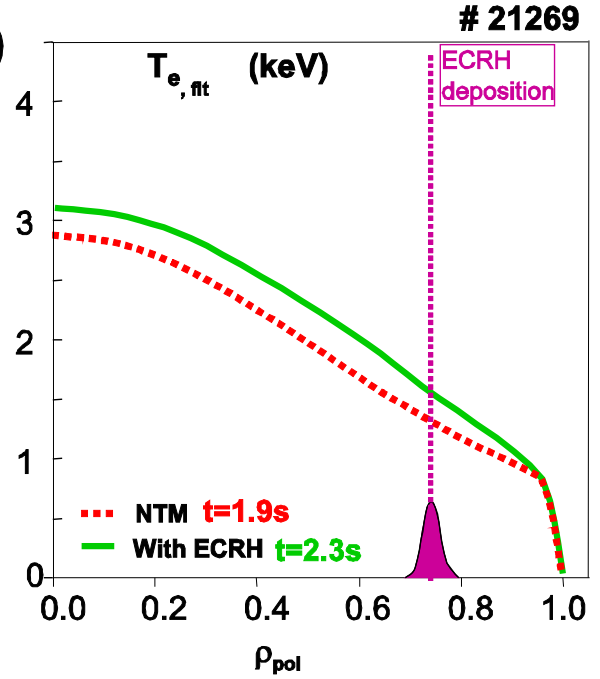

(c)

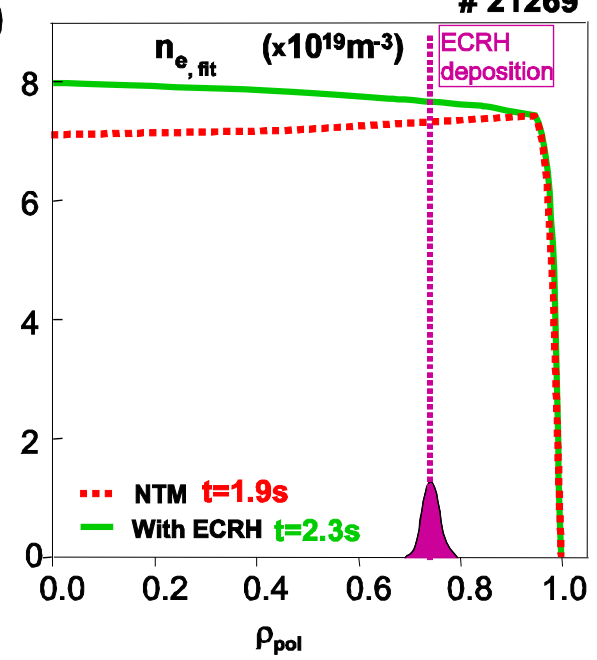

(b)

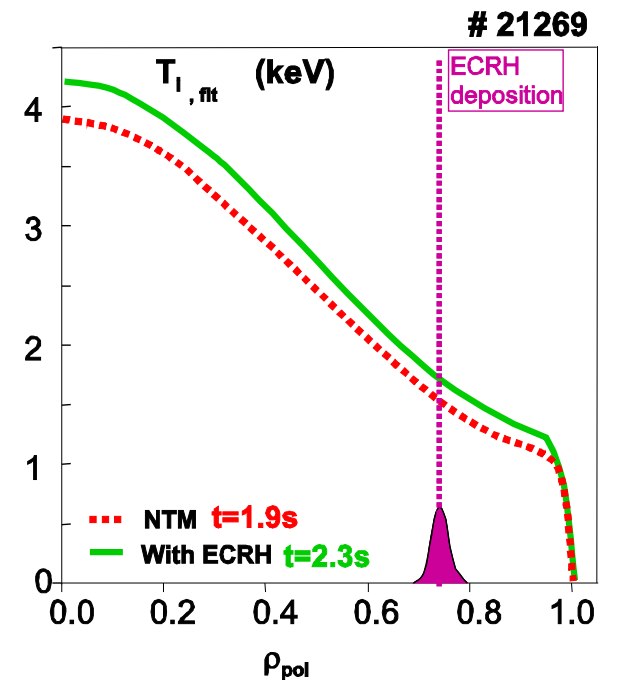

(d)

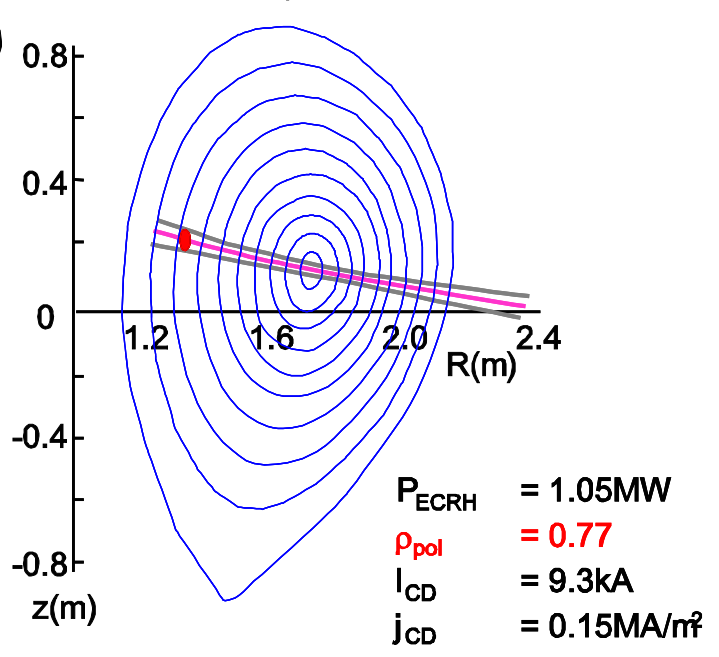

Figure 12: The kinetic profiles obtained for \#21269 (for time traces, see Figure 11). A comparison is made between the period around $t=1.9$ seconds with the $(3,2)$ NTM (dotted curves) and the phase just after the (3,2) NTM is stabilised ( $t=2.3$ seconds, solid curves). Shown are profiles for (a) the electron temperature, (b) the ion temperature and (c) the electron density. These profiles are obtained from fits to various diagnostic data. Shown in (d) is the deposition of the electron cyclotron current drive (ECCD) at $\rho_{\text {pol }}=0.77$ used to stabilise the $(3,2) N T M$, with an indication of the power absorbed, the amount of current driven locally $\left(I_{C D}\right)$ and the local current density achieved by the ECCD ( $\left.j_{C D}\right)$. 

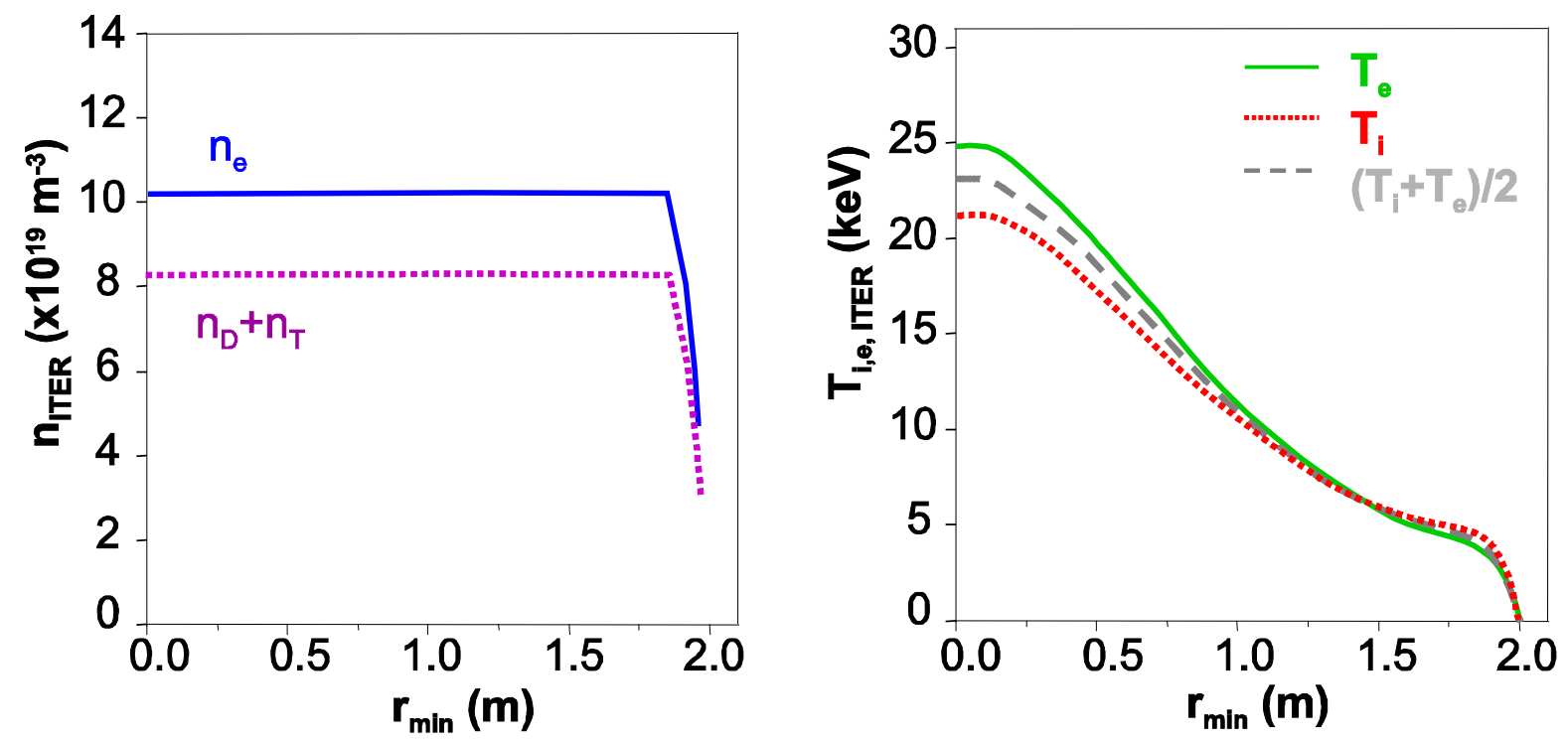

Figure 13: Kinetic profiles obtained in simulations [7] of the ITER reference scenario at 15MA, 5.3T, $<n_{e}>/ n_{G W}=0.85$ and $40 M W$ of input power. On the left, the density profile $\left(n_{e}\right.$, solid curve) used together with the profile for the sum of the deuterium and tritium densities $\left(n_{D}+n_{T}, 50: 50\right.$ mixture, dotted curve). The computed electron temperature ( $T_{e}$, solid curve) and ion temperature ( $T_{i}$, dotted curve) profiles in ITER are shown on the right. The average (dashed curve) of $T_{i}$ and $T_{e}$ is also indicated. 
(a)
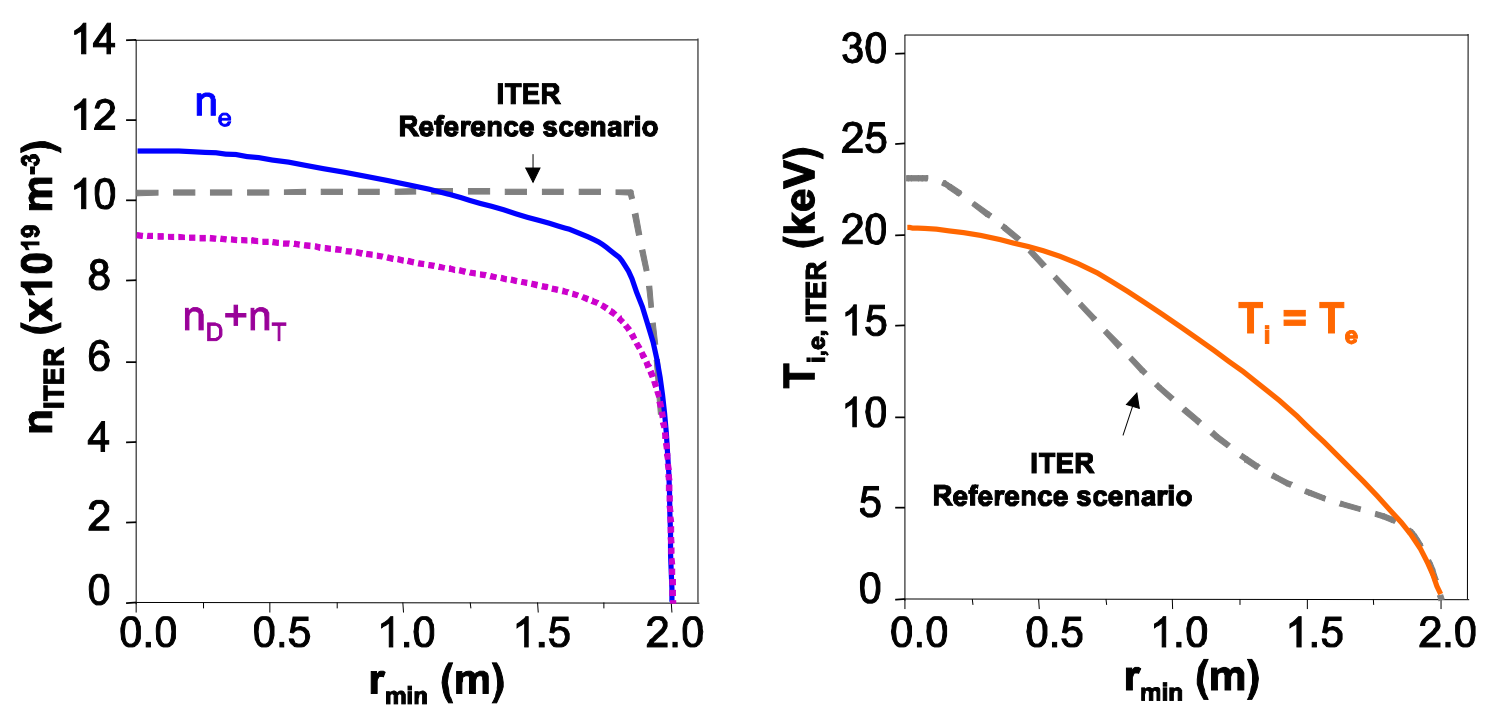

(b)
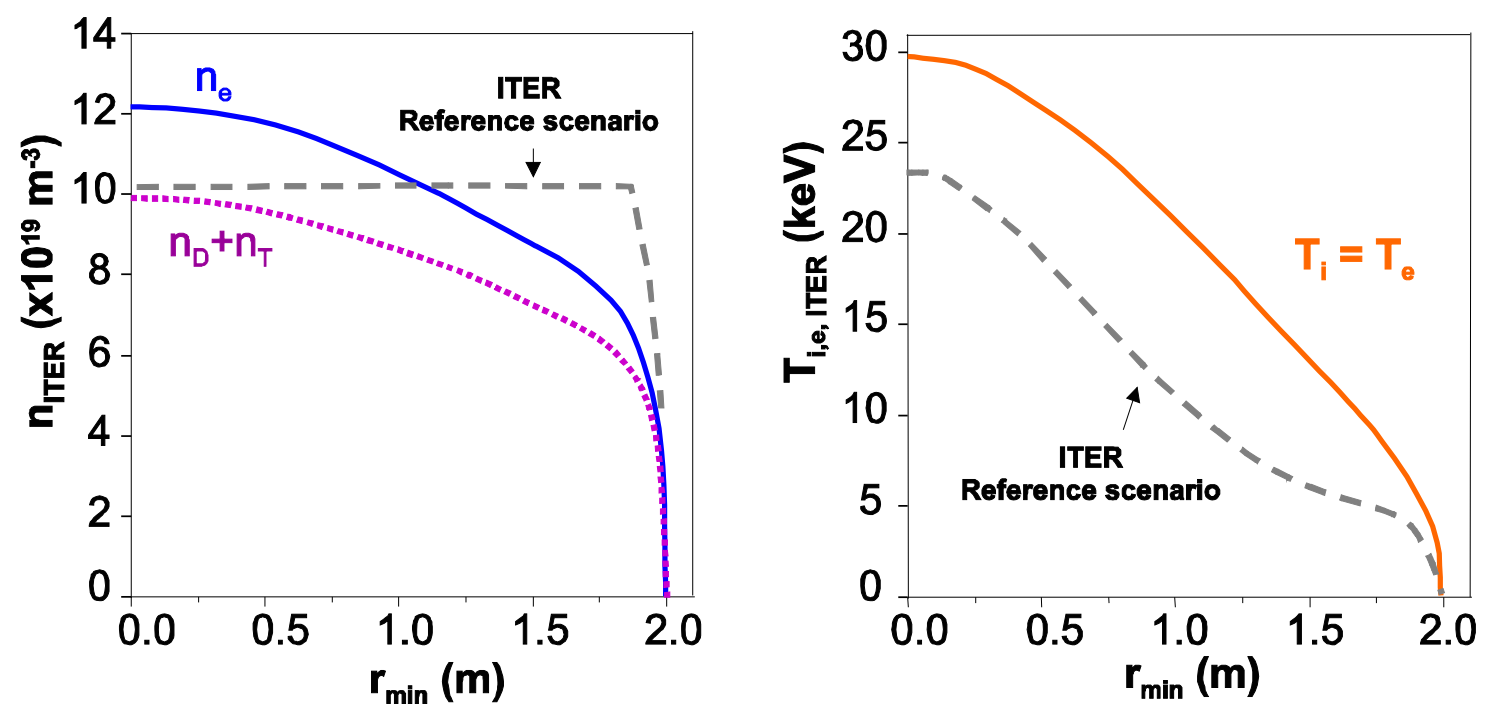
(c)
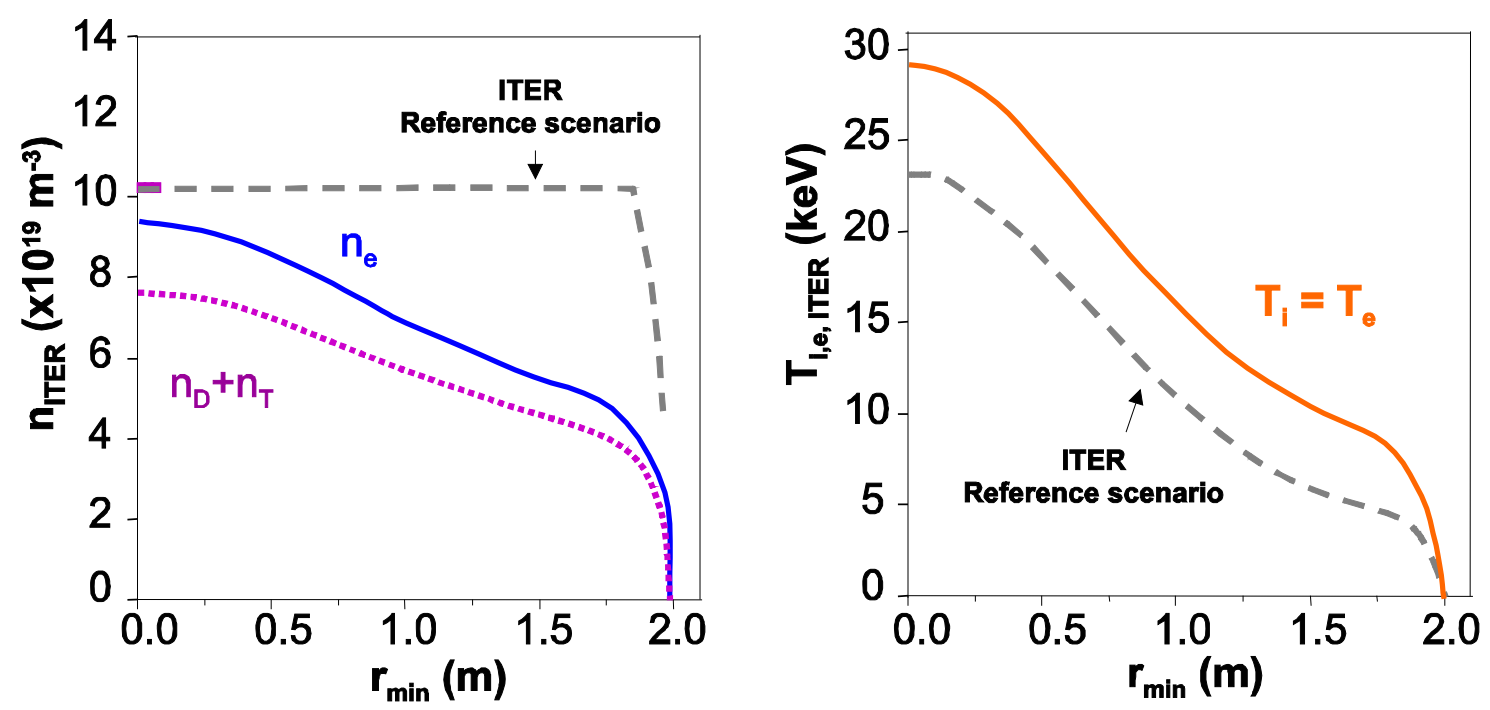

Figure 14: Scaled to ITER, the profiles of three distinct discharges in ASDEX Upgrade: (a)A standard H-mode plasma (\#17847), (b) an improved H-mode (\#20449) and (c) an improved $H$-mode (\#20448) as given in Table III. On the left, the scaled density profiles ( $n_{e}$, solid curve) together with the profiles for the sum of the deuterium and tritium densities $\left(n_{D}+n_{T}\right.$, 50:50 mixture, dotted curve). The scaled ion and electron temperatures are assumed equal (solid curve). The density and temperature profiles are compared to the simulated profiles for the ITER standard scenario at 15MA, shown in Figure 13 (indicated by the grey dashed curves). 


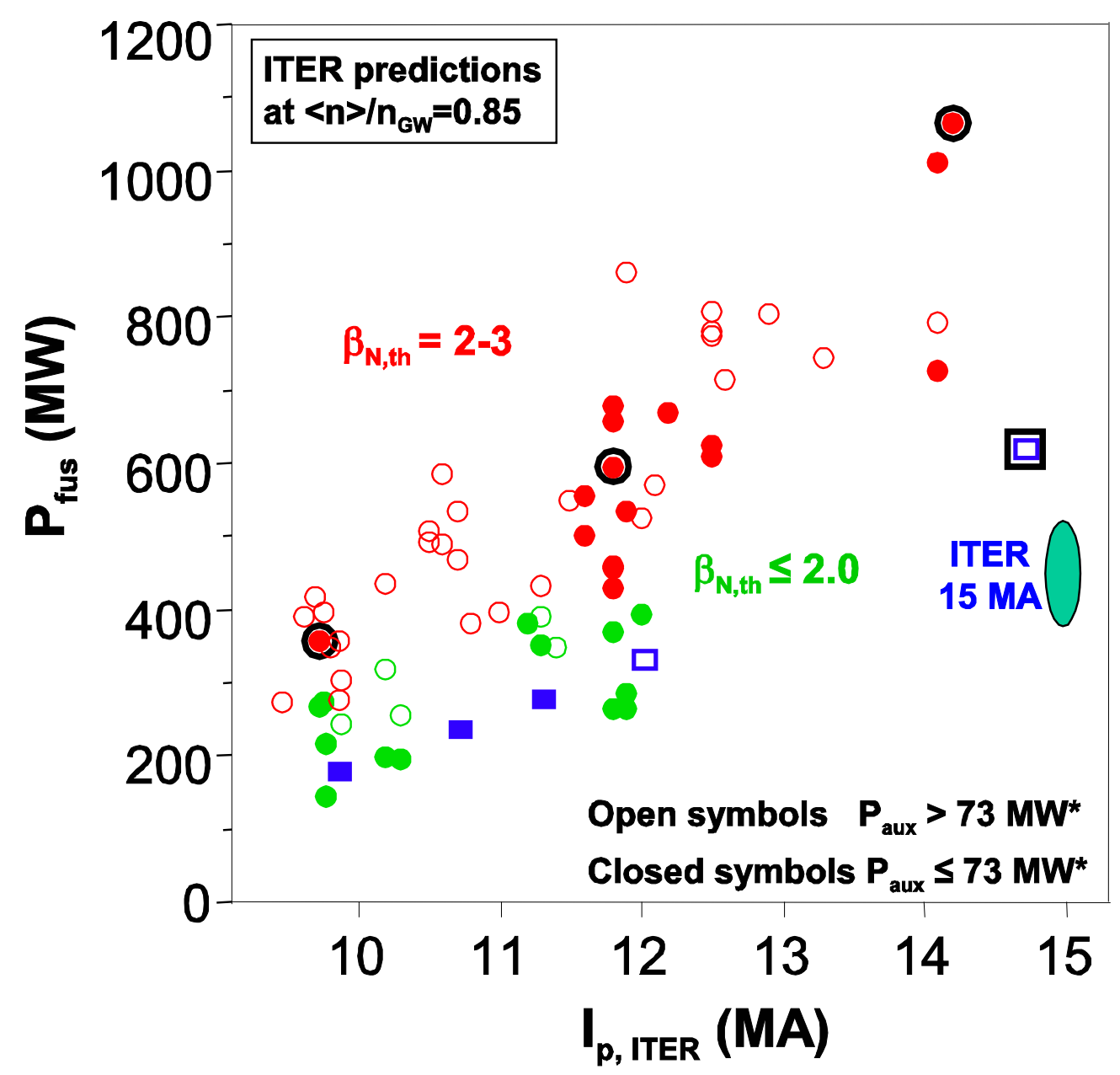

Figure 15: The fusion power in ITER is predicted by scaling the kinetic profile data from ASDEX Upgrade. The dependence on the plasma current used $\left(I_{p, I T E R}\right)$ is shown. The discharges with $\beta_{N, t h} \leq 2$ are indicated by the circles, the discharges that achieve $\beta_{N, t h}=2-3$ are shown by the squares. The blue squares are standard H-modes for a range of $q_{95}$. Closed and open symbols represent discharges where the required input power $\left(P_{\text {aux }}\right)$ is below 73 $M W$ or above $73 M W$ respectively. These power requirements to sustain the $\beta_{N, t h}$ are calculated using the IPB98 $(y, 2)$ scaling expression. The pulses listed in Table III, are denoted by the black circles (improved H-modes) and the black square (standard H-mode) in this plot. 


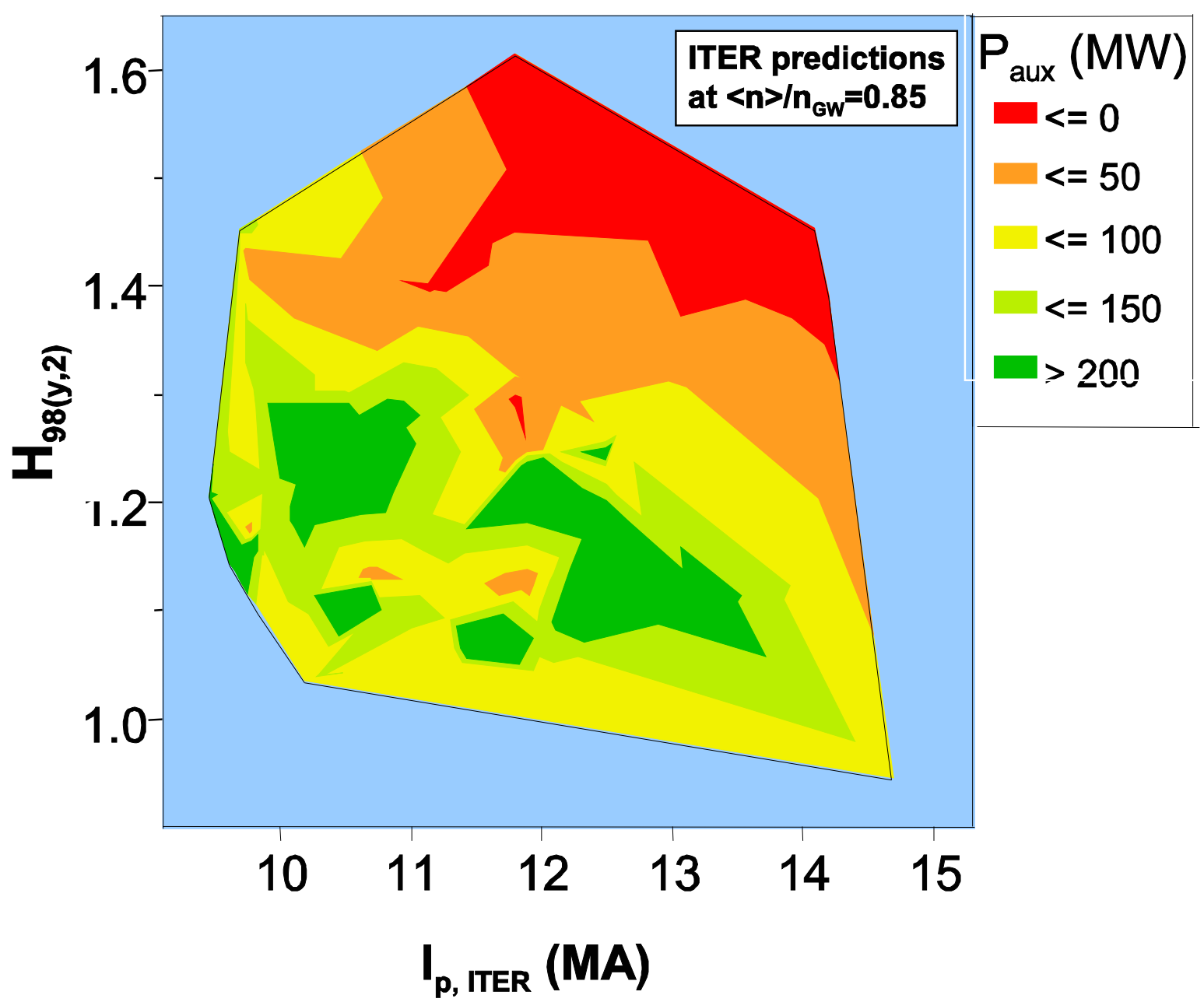

Figure 16: Contour plot of the amount of additional heating required to sustain the projected ITER discharges using the IPB98(y,2) scaling expression. Plotted is $P_{\text {aux }}(M W)$ as a function of the plasma current $\left(I_{p, I T E R}\right)$ and confinement enhancement factor $\left(H_{98(y, 2)}\right)$. 


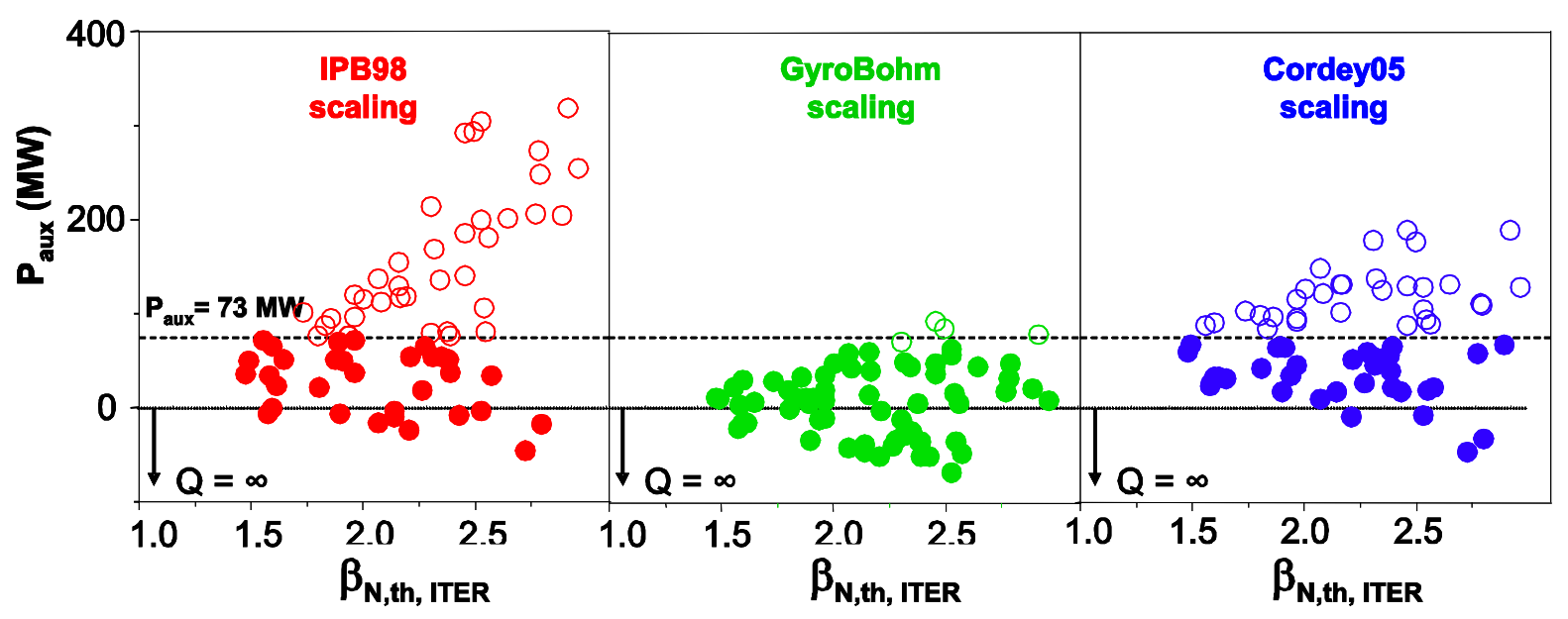

Figure 17: Input power requirements $\left(P_{\text {aux }}\right)$ to sustain the beta $\left(\beta_{N, t h}\right)$ in ITER as obtained in ASDEX Upgrade for three different energy confinement scaling expressions [3,34,35]. The variation of $P_{\text {aux }}$ with beta is shown. Closed and open circles represent discharges where the required input power $\left(P_{\text {aux }}\right)$ is below $73 \mathrm{MW}$ or above $73 \mathrm{MW}$ respectively. 